\title{
Long-term variation in the upper atmosphere as seen in the geomagnetic solar quiet daily variation
}

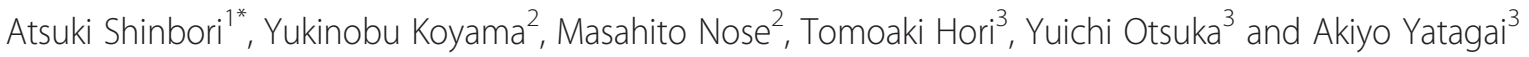

\begin{abstract}
Characteristics of long-term variation in the amplitude of solar quiet (Sq) geomagnetic field daily variation have been investigated using 1-h geomagnetic field data obtained from 69 geomagnetic observation stations within the period of 1947 to 2013. The Sq amplitude observed at these geomagnetic stations showed a clear dependence on the 10- to 12-year solar activity cycle and tended to be enhanced during each solar maximum phase. The Sq amplitude was the smallest around the minimum of solar cycle 23/24 in 2008 to 2009. The relationship between the solar F10.7 index and Sq amplitude was approximately linear but about 53\% of geomagnetic stations showed a weak nonlinear relation to the solar F10.7 index. In order to remove the effect of solar activity seen in the long-term variation of the Sq amplitude, we calculated a linear or second-order fitting curve between the solar F10.7 index and Sq amplitude during 1947 to 2013 and examined the residual Sq amplitude, which is defined as the deviation from the fitting curve. As a result, the majority of trends in the residual Sq amplitude that passed through a trend test showed negative values over a wide region. This tendency was relatively strong in Europe, India, the eastern part of Canada, and New Zealand. The relationship between the magnetic field intensity at 100-km altitude and residual Sq amplitude showed an anti-correlation for about $71 \%$ of the geomagnetic stations. Furthermore, the residual $\mathrm{Sq}$ amplitude at the equatorial station (Addis Ababa) was anti-correlated with the absolute value of the magnetic field inclination. This implies movement of the equatorial electrojet due to the secular variation of the ambient magnetic field.
\end{abstract}

Keywords: Solar quiet geomagnetic field daily variation; Solar activity; Long-term trend; Secular variation; Upper atmosphere

\section{Background}

The geomagnetic field on the ground shows regular variation with a fundamental period of $24 \mathrm{~h}$ during a solar quiet day. This regular variation depends on the local time, latitude, season, and solar cycle, and it is known as the solar quiet (Sq) geomagnetic field daily variation [e.g., Chapman and Bartels 1940; Matsushita 1960; Matsushita and Campbell 1967; Cloutier and Haymes 1968; Richmond et al. 1976; Campbell 1982, 1997; Schlapp and Butcher 1995; Takeda 2002; Torta et al. 2010; Hawary et al. 2012; Yamazaki and Yumoto 2012; Chulliat et al. 2013]. The Sq variation is mainly produced by ionospheric currents flowing in the $\mathrm{E}$ region of the

\footnotetext{
* Correspondence: shinbori@rish.kyoto-u.ac.jp

${ }^{1}$ Research Institute for Sustainable Humanosphere (RISH), Kyoto University, Uji, Japan

Full list of author information is available at the end of the article
}

ionosphere around $105 \mathrm{~km}$. The global pattern of the Sq variation of the $\mathrm{H}$ component of the geomagnetic field shows positive and negative changes in the equatorial and middle-latitude regions around noon, respectively. The Sq current system estimated from the geomagnetic field perturbations consists of two large current vortices: one is an anticlockwise current in the northern hemisphere and the other is a clockwise current in the southern hemisphere [e.g., Richmond et al. 1976; Takeda 2002; Hawary et al. 2012; Yamazaki and Yumoto 2012]. The Sq current is dominant in the daytime ionosphere where ionospheric conductivity is relatively large, and it is driven by electric fields originating from the ionospheric dynamo via the interaction between ionized and neutral particles. The Sq amplitude depends on the height-integrated ionospheric conductivities, the electric field, the neutral wind related to the solar diurnal tide, and the intensity of 
the ambient magnetic field at the E-region height. Therefore, investigations of the long-term variation in the Sq amplitude are important for understanding the physical mechanisms of long-term variation in the upper atmosphere that are related to solar activity and other effects such as secular variation of the ambient magnetic field.

Many investigations of the long-term variation in the Sq amplitude have been performed using long-term geomagnetic field data and several related parameters such as sunspot numbers and the solar F10.7 flux since [Sellek 1980; Schlapp et al. 1990; Macmillan and Droujinina 2007; Torta et al. 2009; Elias et al. 2010]. According to such research, it has been found that the Sq amplitude observed in middle- and low-latitude regions changes with dependence on seasons and solar activity in addition to the activities of solar and lunar tides in the ionosphere. A detailed review of recent works on the long-term variation in the Sq amplitude has been done by Elias et al. (2010). Using long-term observation data of the geomagnetic field obtained at three low- and middlelatitude stations (Apia, Fredericksburg, and Hermanus), Elias et al. (2010) showed that significant long-term trends exist in the Sq amplitude after the removal of seasonal and solar cycle effects and that the Sq amplitude tends to increase over time. They explained more than $50 \%$ of their trend values with the secular variation in the ambient magnetic field and less than $10 \%$ with the increase in greenhouse gases. Recently, De Haro Barbas et al. (2013) performed a comparison between the observed and simulated trends in the Sq amplitude at six geomagnetic stations during 1960 to 2000 using Coupled MagnetosphereIonosphere-Thermosphere (CMIT) simulations. They found that the trends in the observed Sq amplitude are in good agreement with the trends expected from the secular variation in the Earth's main magnetic field. However, in these previous works, global features of the long-term variations in the Sq amplitude have not yet been clarified in detail because of the shortage of long-term observation data obtained from many geomagnetic observatories distributed from both the poles to the equator. Moreover, because Elias et al. (2010) did not show the relationship between the $\mathrm{Sq}$ amplitude and solar activity index (sunspot numbers), it is unknown whether the assumption of the linear relationship used for the deviation of the residual $\mathrm{Sq}$ amplitude is correct or not.

According to Ohm's law, the intensity of the Sq current depends strongly on the height-integrated ionospheric conductivity, the electric field, and the dynamo electric field $(\mathrm{U} \times \mathrm{B})$ obtained from the cross product of neutral wind $(\mathrm{U})$ and the magnetic main field (B). Therefore, under the condition of a constant neutral wind velocity, it can be thought that a decrease of the magnetic field intensity due to the secular variation of the Earth's magnetic field [e.g., Bloxham and Gubbins 1985;
Hongre et al. 1998; Korte and Constable 2011; Nahayo and Kotze 2012; Bhardwaj and Subba Rao 2013] causes a reduction of the $\mathrm{Sq}$ amplitude associated with the weakening of the dynamo field. However, because the height-integrated ionospheric conductivity is also affected by the intensity of the magnetic field, the dependence of the Sq amplitude on the magnetic field is more complicated. Rishbeth (1985) showed that ionospheric conductivities tend to increase by a factor of 35 if the intensity of the magnetic field decreases by a factor 10. He also estimated the heights where the collision frequency is equal to the cyclotron frequency for both electrons and ions in regard to the variation of the magnetic field intensity and found that the height and thickness of the dynamo layer decrease with an increase of the magnetic field. Takeda (1996) also showed an enhancement in the integrated Pedersen and Hall conductivities of approximately 42 and 26 times, respectively, for a decrease in the intensity of the magnetic field by a factor 10. Elias et al. (2010) reported that a decrease of the magnetic field causes an increase in the $\mathrm{Sq}$ amplitude because of an enhancement in the ionospheric conductivities. Using the CMIT model, Cnossen et al. (2012) confirmed that an increase in the ionospheric conductivities could generate long-term trends in the Sq amplitude of a similar order of magnitude to observed trends associated with a reduction in the dipole moment over the past century. Moreover, near the dip equator, the variations in the inclination of the magnetic field lead to a significant change in the $\mathrm{Sq}$ amplitude because the Cowling conductivity [Hirono 1952] is very sensitive to the inclination of the magnetic field. Additionally, the Sq current pattern is organized by magnetic coordinates; so, as the position of the magnetic equator shifts, the whole Sq pattern can be expected to move along. On the basis of CMIT model calculations, Cnossen and Richmond (2013) showed a significant change in the $\mathrm{Sq}$ amplitude due to a shift in the location of the equatorial electrojet in terms of geographical coordinates.

Because the ionospheric conductivities also depend on the electron density in the ionosphere in addition to the magnetic field intensity, it is important to investigate the long-term trends in the upper atmosphere (mesosphere and thermosphere) and ionosphere. The long-term variations in ionospheric parameters such as electron density, ion composition, and temperature have been observed by many researchers [e.g., Roble and Dickinson 1989; Rishbeth 1990; Bremer 1998; Danilov and Mikhailov 1999; Foppiano et al. 1999; Mikhailov and Marin 2000; Danilov 2002; Hall and Cannon 2002; Elias and Ortiz de Adler 2006; Mikhailov 2006; Cnossen and Richmond 2008; Yue et al. 2008; Elias 2009, Elias et al. 2014]. Recent studies on the long-term variations in the upper atmosphere and ionosphere have been reviewed in the papers of 
Qian et al. (2011) and Lastovicka et al. (2012). Danilov and Konstantinova (2012) investigated the long-term trend in the critical frequency of the F2 region of the ionosphere (foF2) during 1990 to 2010 using the observation data obtained from 22 ionospheric stations. They showed that the foF2 trend was negative during all periods and that this tendency was more intense in 1998 to 2010 compared to 1990 to 1997. On the basis of this result, Danilov and Konstantinova (2012) proposed that the temperature variation due to greenhouse cooling in the upper atmosphere plays an important role in the long-term trend of the foF2 in the latter period. However, the model calculation results of the long-term variation in the ionosphere by Rishbeth and Roble (1992) showed an increase in the critical frequency of the $\mathrm{E}$ region of the ionosphere (foE) by $5 \%$ for the case where there is a doubling of atmospheric greenhouse gases. This enhancement in the foE due to the greenhouse effect may lead to a positive trend in the Sq amplitude. The effect of enhanced greenhouse gases on the Sq amplitude was recently simulated by Cnossen (2014), who showed that changes in the ambient magnetic field contribute much more to the long-term trends in the Sq amplitude than enhanced greenhouse gases.

In this paper, characteristics of the long-term variation in the Sq amplitude related to a change in the upper atmosphere and ionosphere were investigated using long-term observation data that were obtained continuously from many geomagnetic observatories. The present study attempts to establish a global picture of the long-term trend in the $\mathrm{Sq}$ amplitude and to clarify the mechanism in comparison with the long-term trend in the magnetic field intensity and inclination derived from the International Geomagnetic Reference Field (IGRF)-11 model [Finlay et al. 2010]. Moreover, from a correlation analysis between the Sq amplitude and solar activity data, we also investigate whether the relationship between these parameters is linear or nonlinear.

\section{Methods}

We used the long-term observation data of the $\mathrm{H}$ component of the geomagnetic field with a time resolution of $1 \mathrm{~h}$ that were provided by the World Data Center for Geomagnetism, Kyoto University. At this site, geomagnetic field data obtained at 274 geomagnetic stations are now available. However, because the Sq current driven by the ionospheric dynamo in the $\mathrm{E}$ region of the ionosphere, which is due to solar tidal waves, is dominant in the region from the equator to middle latitudes, we only analyzed the geomagnetic field data obtained from 213 geomagnetic stations under the conditions that they are located in a region of less than $60^{\circ}$ (geomagnetic latitude) and that the available period of geomagnetic field data overlaps with that of the solar radio flux (F10.7) data, which are available after 1947. Moreover, we only used geomagnetic field data if it satisfied the condition that the available period is more than 30 years and that the valid monthly data points are more than 360 after cutting the edge of the data sets so that full years are included for the present correlation and trend analyses. The final number of geomagnetic stations used in the present analysis was 69 , and the data obtained from the 69 geomagnetic stations satisfied all of the above conditions. Table 1 shows the location of the 69 geomagnetic stations as a function of latitude and longitude in terms of geographic and geomagnetic coordinates, the period of availability after 1947, and the trend (slope and its standard error) in the residual Sq amplitude, which is given in units of $\mathrm{nT} /$ year. The locations of these geomagnetic stations plotted as functions of geographical latitude and longitude are shown in Figure 1. As this figure shows, these geomagnetic observatories are distributed over a wide region ranging from the middle latitudes to the equator.

For identification of geomagnetic quiet days, we used the geomagnetic activity Kp index with a 3-h resolution, which was provided by the GeoForschungsZentrum (GFZ, Potsdam, Germany) Potsdam. The Kp index is available after 1 January 1932. As a good indicator of solar activity, we adopted the daily mean solar F10.7 radio flux data provided by the Space Physics Interactive Data Resource (http://spidr.ngdc.noaa.gov/spidr/). The major reason why we used the solar F10.7 radio flux instead of sunspot numbers is that sunspot numbers continuously tend to zero during the solar minimum (for example, the 23/24 solar cycle minimum). In this case, we cannot correctly perform a correlation analysis between the Sq amplitude and solar activity index in order to derive the residual $\mathrm{Sq}$ amplitude to remove the solar activity dependence. The solar F10.7 flux also has a more direct physical link to solar extreme ultraviolet (EUV) emissions that cause ionization of the upper atmosphere. In the present data analysis, we took advantage of a metadata database search system [Abe et al. 2014] and the Inter-university Upper Atmosphere Global Observation NETwork (IUGONET) data analysis software (UDAS) [Tanaka et al. 2013] for ground-based observations of the upper atmosphere developed in the IUGONET project [Hayashi et al. 2013; Yatagai et al. 2014].

In order to obtain the daily Sq amplitude of the $\mathrm{H}$ component, we calculated the difference between the maximum and minimum values of the daily variation for each quiet day and then averaged the Sq amplitude over the quiet days for each month. Here, we identified a quiet day as a day when the maximum value of the Kp index was less than 4 for that day. The solar activity dependence included in the long-term variation in the Sq amplitude was removed by calculating the deviation from a least-square fitted curve derived by a correlation analysis between the Sq amplitude and solar F10.7 index. 
Table 1 List of geographic and geomagnetic locations of 69 geomagnetic observatories, their data availability periods, and trends in the residual Sq amplitude

\begin{tabular}{|c|c|c|c|c|c|c|}
\hline Station name & $\begin{array}{l}\text { GLAT } \\
\text { [degree] }\end{array}$ & $\begin{array}{l}\text { GLONG } \\
\text { [degree] }\end{array}$ & $\begin{array}{l}\text { GMLAT } \\
\text { [degree] }\end{array}$ & $\begin{array}{l}\text { GMLONG } \\
\text { [degree] }\end{array}$ & $\begin{array}{l}\text { Data availability } \\
\text { period after } 1947\end{array}$ & Trend [nT/year] \\
\hline Addis Ababa & 9.035 & 38.766 & 5.36 & 112.16 & $1958 / 1 / 1$ to $2010 / 12 / 31$ & $-0.125 \pm 0.084$ \\
\hline Alibag & 18.638 & 72.872 & 10.37 & 146.55 & $1947 / 1 / 1$ to $2011 / 12 / 31$ & $-0.122 \pm 0.043$ \\
\hline Alma Ata & 43.25 & 76.92 & 34.5 & 153.04 & $1963 / 5 / 1$ to $2010 / 12 / 31$ & No trend \\
\hline Apia & -13.807 & 188.225 & -15.25 & 263.01 & $1947 / 1 / 1$ to $2009 / 12 / 31$ & No trend \\
\hline Aregentine Island & -65.25 & 295.73 & -55.33 & 5.84 & $1957 / 3 / 13$ to $2009 / 12 / 31$ & No trend \\
\hline Bangui & 4.333 & 18.566 & 4.13 & 91.53 & $1955 / 1 / 1$ to $2007 / 12 / 31$ & No trend \\
\hline Beijing & 40 & 116.2 & 30.11 & 187.45 & $1957 / 1 / 1$ to $1993 / 12 / 31$ & $0.275 \pm 0.172$ \\
\hline Belsk & 51.837 & 20.792 & 50.24 & 105.26 & $1966 / 1 / 1$ to $2010 / 12 / 31$ & $-0.074 \pm 0.062$ \\
\hline Boulder & 40.13 & 254.76 & 48.24 & 321.28 & $1967 / 1 / 1$ to $2010 / 12 / 31$ & No trend \\
\hline Chambon-La-Foret & 48.025 & 2.261 & 49.75 & 85.8 & $1947 / 1 / 1$ to $2010 / 12 / 31$ & $-0.216 \pm 0.035$ \\
\hline Crozet & -46.431 & 51.86 & -51.31 & 114.05 & $1974 / 1 / 1$ to $2009 / 12 / 31$ & No trend \\
\hline Dourbes & 50.1 & 4.6 & 51.34 & 88.99 & $1957 / 7 / 1$ to $2010 / 12 / 31$ & $-0.110 \pm 0.107$ \\
\hline Eskdalemuir & 55.317 & 356.8 & 57.69 & 83.76 & $1947 / 1 / 1$ to $2010 / 12 / 31$ & $-0.216 \pm 0.067$ \\
\hline Eyrewell & -43.41 & 172.35 & -46.96 & 254 & $1978 / 8 / 1$ to $2010 / 12 / 31$ & $-0.118 \pm 0.155$ \\
\hline Fredericksburg & 38.2 & 282.63 & 48.14 & 353.93 & $1956 / 1 / 1$ to $2010 / 12 / 31$ & No trend \\
\hline Furstenfeldbruck & 48.165 & 11.277 & 48.32 & 94.73 & $1947 / 1 / 1$ to $2010 / 12 / 31$ & $-0.099 \pm 0.034$ \\
\hline Gnangara & -31.78 & 115.947 & -41.65 & 189.3 & $1957 / 7 / 1$ to $2010 / 12 / 31$ & $-0.027 \pm 0.033$ \\
\hline Guam & 13.59 & 144.87 & 5.56 & 216.08 & $1957 / 7 / 6$ to $2010 / 12 / 31$ & No trend \\
\hline Guangzhou & 23.093 & 113.343 & 13.15 & 185.25 & $1960 / 1 / 1$ to $2009 / 12 / 31$ & No trend \\
\hline Hartebeesthoek & -25.883 & 27.707 & -27.18 & 94.97 & $1972 / 1 / 1$ to $2009 / 12 / 31$ & No trend \\
\hline Hartland & 51 & 355.517 & 53.78 & 80.25 & $1957 / 1 / 1$ to $2010 / 12 / 31$ & $-0.135 \pm 0.050$ \\
\hline Hel & 54.608 & 18.817 & 53.23 & 104.68 & $1966 / 1 / 1$ to $2009 / 12 / 31$ & No trend \\
\hline Hermanus & -34.425 & 19.225 & -34.08 & 84.63 & $1947 / 1 / 1$ to $2012 / 12 / 31$ & $0.029 \pm 0.024$ \\
\hline Honolulu & 21.32 & 202 & 21.71 & 270.27 & $1947 / 1 / 1$ to $2012 / 12 / 31$ & $-0.052 \pm 0.030$ \\
\hline Huancayo & -12.038 & 284.682 & -2.07 & 356.97 & $1947 / 1 / 1$ to $2009 / 12 / 31$ & No trend \\
\hline Hurbanovo & 47.873 & 18.19 & 46.85 & 101.24 & $1957 / 1 / 1$ to $2011 / 12 / 31$ & $-0.063 \pm 0.032$ \\
\hline Irkutsk & 52.167 & 104.45 & 42.2 & 177.24 & $1957 / 7 / 1$ to $2010 / 12 / 31$ & No trend \\
\hline Istanbul-Kandilli & 41.063 & 29.062 & 38.42 & 109.32 & $1950 / 1 / 1$ to $1997 / 12 / 31$ & $-0.106 \pm 0.078$ \\
\hline Kakioka & 36.232 & 140.186 & 27.65 & 209.21 & $1947 / 1 / 1$ to $2013 / 12 / 31$ & $-0.061 \pm 0.025$ \\
\hline Kanoya & 31.424 & 130.88 & 22.17 & 201.19 & $1958 / 1 / 1$ to $2013 / 12 / 31$ & $-0.043 \pm 0.033$ \\
\hline Kanozan & 35.256 & 139.956 & 26.66 & 209.11 & $1962 / 4 / 1$ to $2013 / 12 / 31$ & No trend \\
\hline Kiev & 50.72 & 30.3 & 47.61 & 113.55 & $1958 / 7 / 1$ to $2009 / 12 / 31$ & $0.093 \pm 0.095$ \\
\hline L'Aquila & 42.383 & 13.317 & 42.36 & 94.68 & $1960 / 1 / 1$ to $2009 / 12 / 31$ & No trend \\
\hline Leningrad & 59.95 & 30.7 & 56.41 & 118.08 & $1948 / 1 / 1$ to $1988 / 12 / 31$ & No trend \\
\hline Lovo & 59.344 & 17.824 & 57.9 & 106.35 & $1947 / 1 / 1$ to $2004 / 12 / 31$ & $-0.126 \pm 0.110$ \\
\hline Lvov & 49.9 & 23.75 & 47.88 & 107.22 & $1957 / 7 / 1$ to $2009 / 12 / 31$ & No trend \\
\hline M'Bour & 14.384 & 343.033 & 19.9 & 57.83 & $1952 / 3 / 1$ to $2010 / 12 / 31$ & $0.133 \pm 0.048$ \\
\hline Memambetsu & 43.91 & 144.189 & 35.63 & 211.74 & $1957 / 7 / 1$ to $2013 / 8 / 31$ & No trend \\
\hline Minsk & 54.1 & 26.52 & 51.47 & 111.49 & $1961 / 1 / 1$ to $1994 / 12 / 31$ & $0.152 \pm 0.103$ \\
\hline Moscow & 55.467 & 37.312 & 51.12 & 121.66 & $1957 / 7 / 1$ to $2005 / 12 / 31$ & No trend \\
\hline Newport & 48.27 & 242.88 & 54.76 & 305.48 & $1966 / 4 / 1$ to $2010 / 12 / 31$ & No trend \\
\hline Niemegk & 52.072 & 12.675 & 51.84 & 97.71 & $1947 / 1 / 1$ to $2011 / 12 / 31$ & $-0.120 \pm 0.038$ \\
\hline Novosibirsk & 55.03 & 82.9 & 45.8 & 159.76 & $1967 / 1 / 1$ to $2010 / 12 / 31$ & No trend \\
\hline
\end{tabular}


Table 1 List of geographic and geomagnetic locations of 69 geomagnetic observatories, their data availability periods, and trends in the residual Sq amplitude (Continued)

\begin{tabular}{|c|c|c|c|c|c|c|}
\hline Nurmijarvi & 60.508 & 24.655 & 57.89 & 113.15 & $1953 / 1 / 1$ to $2009 / 12 / 31$ & No trend \\
\hline Odessa & 46.78 & 30.88 & 43.69 & 112.71 & $1957 / 7 / 1$ to $1991 / 12 / 31$ & $0.103 \pm 0.086$ \\
\hline Ottawa & 45.403 & 284.448 & 55.37 & 355.88 & $1968 / 7 / 1$ to $2010 / 12 / 31$ & $-0.251 \pm 0.197$ \\
\hline Papeete & -17.567 & 210.426 & -15.13 & 285.49 & $1968 / 1 / 1$ to $2009 / 12 / 31$ & $-0.034 \pm 0.089$ \\
\hline Pilar & -31.67 & 296.12 & -21.78 & 7.64 & $1947 / 1 / 1$ to $1985 / 12 / 31$ & $0.222 \pm 0.111$ \\
\hline Port Aux Francais & -49.353 & 70.262 & -56.81 & 133.56 & $1957 / 1 / 1$ to $2009 / 12 / 31$ & $0.132 \pm 0.135$ \\
\hline Port Moresby & -9.46 & 147.16 & -17.1 & 220.9 & $1958 / 4 / 1$ to $1991 / 12 / 31$ & No trend \\
\hline Rude Skov & 55.483 & 12.457 & 55.14 & 99.17 & $1947 / 1 / 1$ to $1981 / 12 / 31$ & $-0.214 \pm 0.147$ \\
\hline San Juan & 18.11 & 293.85 & 28.04 & 6.54 & $1947 / 1 / 1$ to $2012 / 12 / 31$ & No trend \\
\hline She-Shan & 31.097 & 121.187 & 21.36 & 192.31 & $1950 / 1 / 1$ to $2006 / 12 / 31$ & $-0.051 \pm 0.043$ \\
\hline St. Johns & 47.595 & 307.323 & 56.87 & 24.37 & $1968 / 8 / 1$ to $2009 / 12 / 31$ & $-0.276 \pm 0.153$ \\
\hline Tananarive & -18.917 & 47.552 & -23.62 & 116.33 & $1957 / 1 / 1$ to $2007 / 12 / 31$ & No trend \\
\hline Tashkent & 41.333 & 69.617 & 33.23 & 146.31 & $1957 / 7 / 1$ to $1991 / 12 / 31$ & $0.087 \pm 0.080$ \\
\hline Tbilisi & 42.08 & 44.7 & 37 & 124.04 & $1957 / 1 / 1$ to $2001 / 12 / 31$ & $-0.267 \pm 0.391$ \\
\hline Teoloyucan & 19.746 & 260.807 & 28.57 & 330.92 & $1965 / 1 / 1$ to $2008 / 12 / 31$ & $0.439 \pm 0.153$ \\
\hline Trivandrum & 8.48 & 76.95 & -0.12 & 149.54 & $1958 / 1 / 1$ to $1999 / 12 / 31$ & $-0.198 \pm 0.145$ \\
\hline Tsumeb & -19.202 & 17.584 & -18.87 & 86.35 & $1964 / 8 / 1$ to $2008 / 12 / 31$ & No trend \\
\hline Tucson & 32.17 & 249.27 & 39.73 & 316.74 & $1947 / 1 / 1$ to $2010 / 12 / 31$ & No trend \\
\hline Valentia & 51.93 & 349.75 & 55.65 & 74.7 & $1957 / 7 / 1$ to $2010 / 12 / 31$ & $-0.088 \pm 0.076$ \\
\hline Vassouras & -22.4 & 316.35 & -13.56 & 27.05 & $1949 / 1 / 1$ to $2009 / 12 / 31$ & $-0.315 \pm 0.123$ \\
\hline Victoria & 48.52 & 236.58 & 54.08 & 298.38 & $1957 / 7 / 1$ to $2010 / 12 / 31$ & $0.035 \pm 0.059$ \\
\hline Vladivostok & 43.697 & 132.16 & 34.49 & 201.23 & $1957 / 7 / 1$ to $1989 / 12 / 31$ & $0.119 \pm 0.119$ \\
\hline Wingst & 53.743 & 9.073 & 54.07 & 95.05 & $1947 / 1 / 1$ to $2010 / 12 / 31$ & $-0.137 \pm 0.047$ \\
\hline Witteveen & 52.813 & 6.668 & 53.59 & 92.26 & $1947 / 1 / 1$ to $1984 / 12 / 31$ & $-0.148 \pm 0.105$ \\
\hline Yakutsk & 62.02 & 129.72 & 52.59 & 196.77 & $1957 / 7 / 1$ to $2009 / 12 / 31$ & No trend \\
\hline Yuzhno Sakhalinsk & 46.95 & 142.717 & 38.51 & 209.97 & $1957 / 7 / 1$ to $1988 / 12 / 31$ & No trend \\
\hline
\end{tabular}

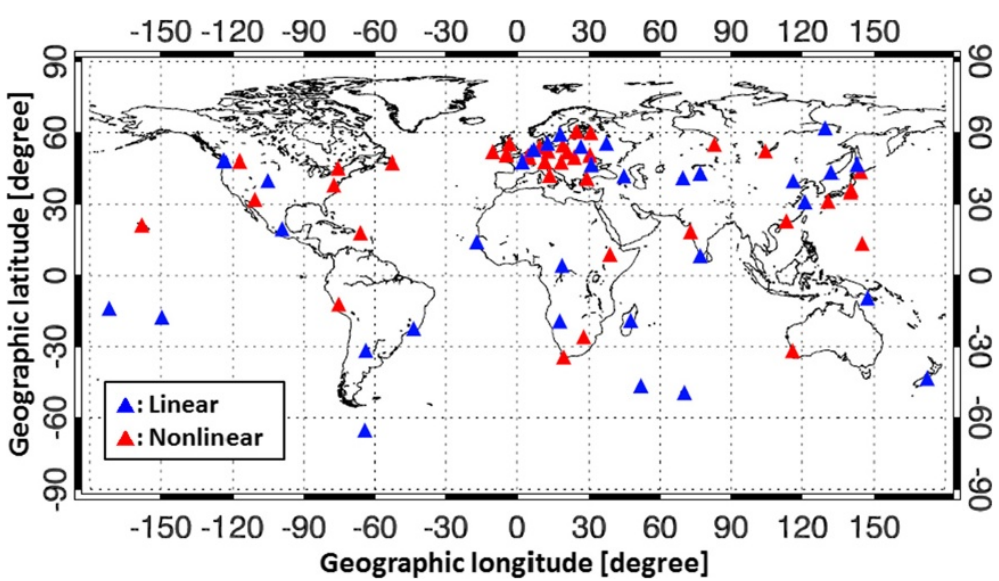

Figure 1 Spatial distribution of the geomagnetic stations. Spatial distribution of the geomagnetic stations that observed the linear or nonlinear relationships between the solar F10.7 index and Sq amplitude. The geomagnetic stations are plotted as blue and red triangles on the world map. The blue and red colors indicate the linear and nonlinear relationships, respectively. 
In this analysis, we used the monthly mean solar F10.7 index.

\section{Results and discussion}

\section{Solar activity dependence on the Sq amplitude}

In this section, in order to investigate the characteristics of long-term variation in the $\mathrm{Sq}$ amplitude derived from the $\mathrm{H}$-component of the geomagnetic field for solar activity, we compared the solar F10.7 index with the Sq amplitude in three latitudinal zones: the equatorial $\left(\mid\right.$ GMLAT $\left.\mid<10^{\circ}\right)$, low-latitude $\left(10^{\circ} \leq \mid\right.$ GMLAT $\left.\mid<30^{\circ}\right)$, and middle-latitude $\left(30^{\circ} \leq|\mathrm{GMLAT}|<60^{\circ}\right)$ regions. Here, GMLAT represents the geomagnetic latitude. Figures 2, 3, and 4 show the monthly mean solar F10.7 index and Sq amplitude obtained at four geomagnetic stations located in the above three latitudinal regions, respectively. The vertical dashed lines indicate the times of the solar F10.7 minimum. The time interval of each plot is 70 years (1945 to 2015).

\section{(a) Equatorial region}

In the first panel in Figure 2 and also Figures 3 and 4, the solar F10.7 index shows a clear variation between 70 and $290 \mathrm{sfu}$ with a period of approximately 10 to 12 years. The maximum value of the F10.7 index varied between 140 and $290 \mathrm{sfu}$ for each solar cycle, but the minimum value did not show a large variation during 1947 to 2014. The amplitude of the short-term variation tended to be enhanced significantly during high solar activity. The value of the solar F10.7 index was the largest around 1957, while it was the smallest around 2008.

The second to fifth panels in this figure show the monthly mean $\mathrm{Sq}$ amplitude derived from the $\mathrm{H}$ component of the geomagnetic field at Addis Ababa (AAE) $\left(5.36^{\circ}, 1.82^{\circ}\right.$ in geomagnetic and dip latitudes), Bangui (BNG) $\left(4.13^{\circ},-16.82^{\circ}\right)$, Guam (GUA) $\left(5.56^{\circ}, 12.46^{\circ}\right)$, and Trivandrum (TRD) $\left(-0.12^{\circ}, 2.20^{\circ}\right)$, respectively. The Sq amplitude at the Addis Ababa and Trivandrum stations near the dip equator was approximately 1.5 to 1.8 times larger than that at the other stations off the dip equator. The enhancement of the Sq amplitude was caused by a significant enhancement of ionospheric conductivity due to the Cowling effect [Hirono 1952]. The most prominent long-term variation of the Sq amplitude at each station was a 10- to 12-year periodic oscillation, which corresponds to the signature of the solar F10.7 index as seen in the first panel in Figure 2. The amplitude of this oscillation tended to be large at the Addis Ababa and Trivandrum stations near the dip equator. Moreover, the Sq amplitude displayed short-term variation with a period of 1 year or less. The amplitude of the short-term variation was also large near the dip equator. The Sq amplitude at the Addis Ababa and Guam stations was the smallest around 2008, which corresponds to the solar cycle 23/24 minimum.

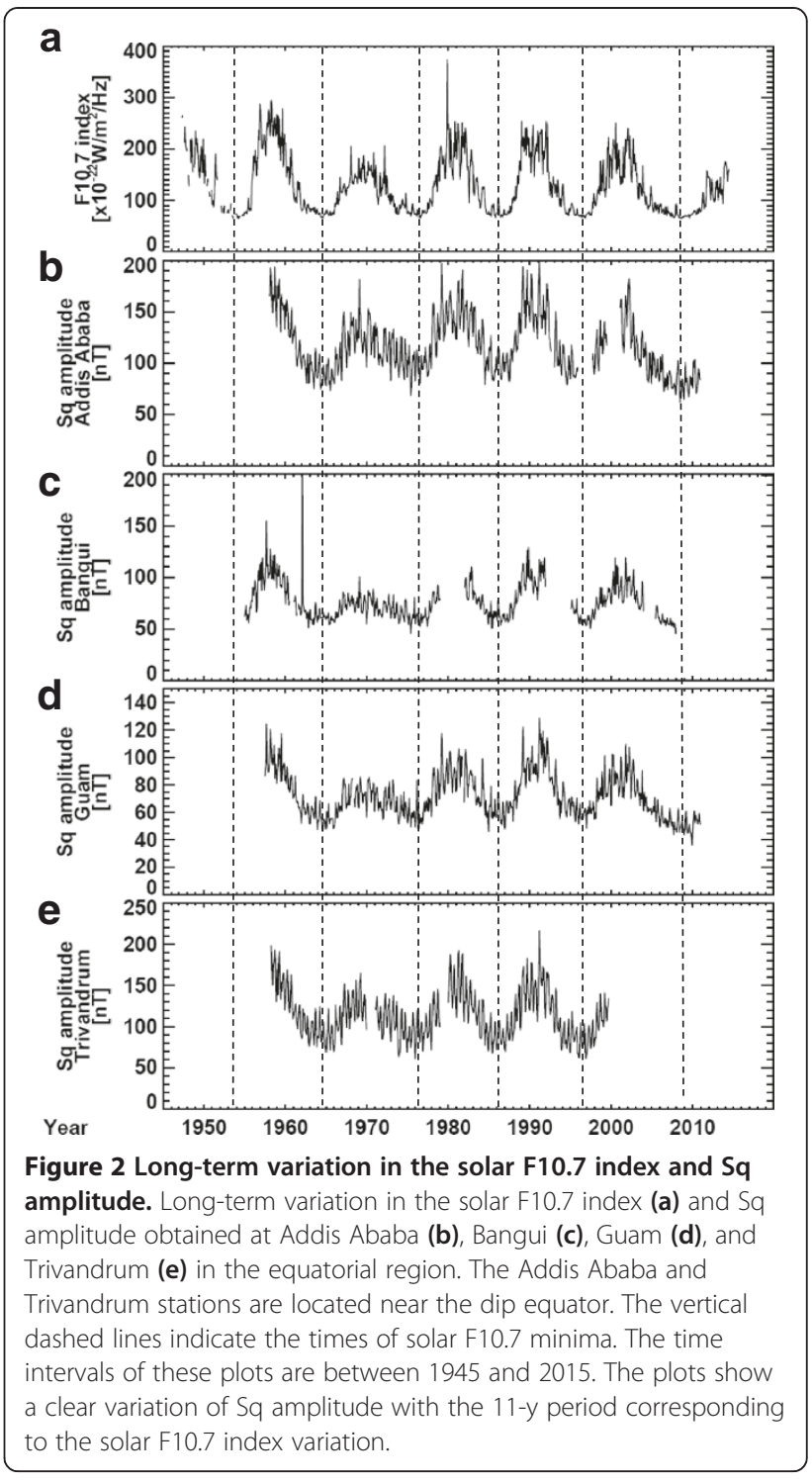

\section{(b) Low-latitude regions}

The second to fifth panels in Figure 3 show the monthly mean Sq amplitude at Alibag (ABG) (10.37 in geomagnetic latitude), Apia (API) $\left(-15.25^{\circ}\right)$, Kakioka (KAK) $\left(27.65^{\circ}\right)$, and San Juan (SJG) $\left(28.04^{\circ}\right)$ in the low-latitude region, respectively. The Sq amplitude in the low latitude as well as in the equatorial region (Figure 2) showed a 10- to 12-year oscillation, which resembled the variation of the solar F10.7 index. The Sq amplitude was the smallest around 2008 to 2010 at all stations. The short-term variation with a period of 1 year or less seemed to correspond to the semi-annual or annual variation. Moreover, the annual variation in $\mathrm{Sq}$ amplitude at Apia tended to be large during each solar maximum phase as shown in the third panel in Figure 3. 


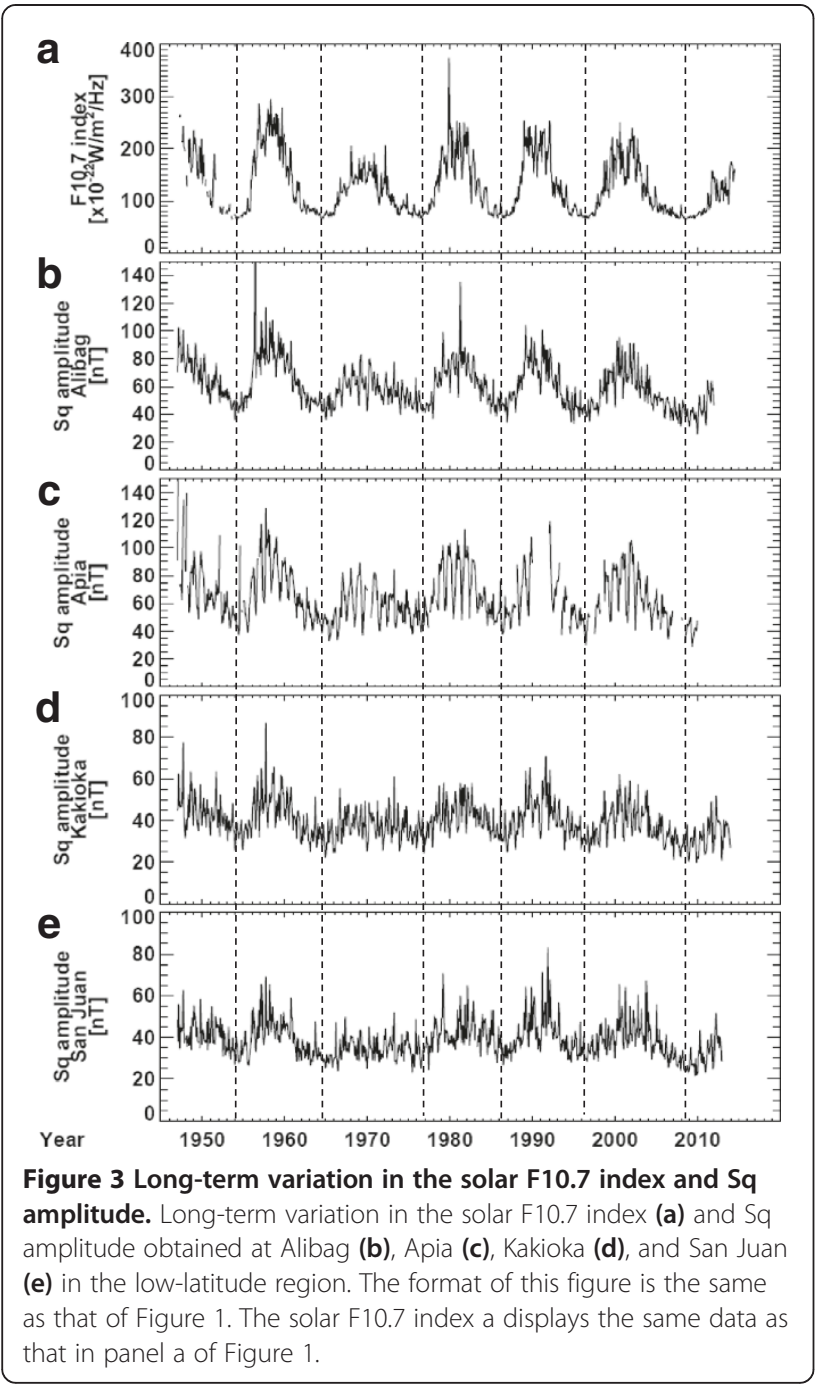

\section{(c) Middle-latitude regions}

The second to fifth panels in Figure 4 show the monthly mean Sq amplitude at Chambon-La-Foret (CLF) $\left(47.75^{\circ}\right.$ in geomagnetic latitude), Niemegk (NGK) $\left(54.57^{\circ}\right)$, Furstenfeldbruck (FUR) $\left(48.32^{\circ}\right)$, and Memanbetsu (MMB) $\left(35.63^{\circ}\right)$ in the middle-latitude region, respectively. The Sq amplitude in the middle-latitude region displayed the similar variation (semi-annual, annual, and solar cycle variations) to that in the equatorial and low-latitude regions (Figures 2 and 3). The Sq amplitude was the smallest around 2008 to 2010 in all stations. The response of solar activity to the Sq amplitude at the ChambonLa-Foret, Niemegk, and Furstenfeldbruck stations tends to be relatively small compared with that at the Memanbetsu station located in the lower latitude. Especially, the Sq amplitude at these geomagnetic stations was not enhanced significantly in a way that corresponded to the maximum phase of solar cycle 20 (1965 to 1975). However, a longterm trend in the Sq amplitude at Chambon-La-Foret can

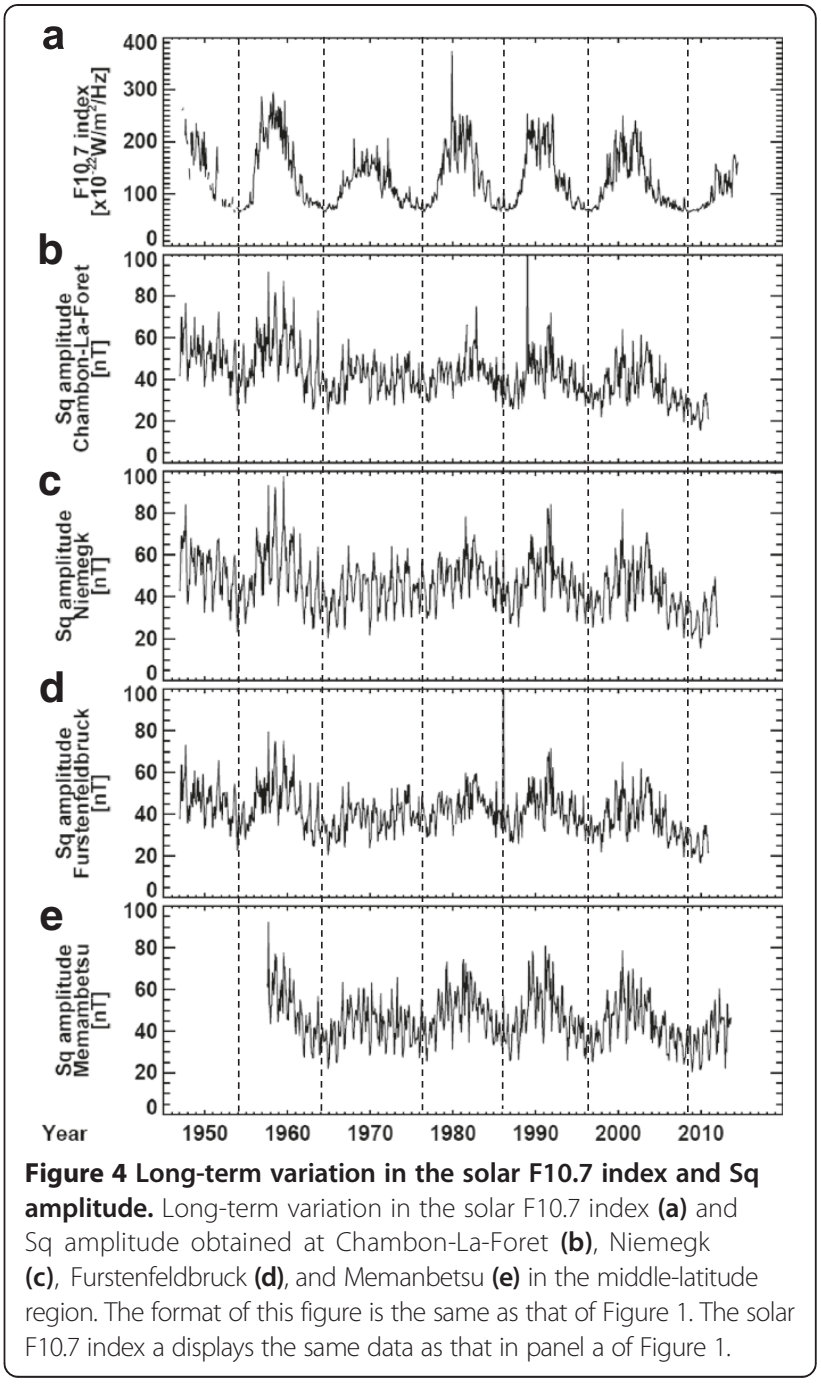

be seen in the second panel in Figure 4. The Sq amplitude tended to decrease over time.

\section{Correlation between the Sq amplitude and solar F10.7 index}

In order to investigate the relationship between the solar F10.7 index and Sq amplitude obtained in the equatorial, low-, and middle-latitude regions, we performed a correlation analysis using a statistical analysis package included in the IUGONET data analysis tool. In this statistical analysis, we first tested whether the linear regression line $(y=a x+b)$ or the second-order fitted curve $(y=$ $\left.\mathrm{cx}^{2}+\mathrm{dx}+\mathrm{e}\right)$ was more suitable for the correlation between the monthly mean solar F10.7 index and Sq amplitude using a statistical F-test for the coefficients of the new additional terms of the fitted curves. The variables $\mathrm{x}$ and $\mathrm{y}$ are the F10.7 index and Sq amplitude, respectively. Details of the fitting and $F$-test procedures used in the present data analysis have been described in the book 'Data Reduction and Error Analysis for the 
Physical Sciences' by Bevington and Robinson (2003). In the present $F$-test, we made a null hypothesis that the coefficient for the new additional term is zero $(c=0)$, compared with the linear regression line, and tested the following value $F_{x}$ with a significance of $95 \%$ :

$$
F_{X}=\frac{\chi^{2}(m)-\chi^{2}(m+1)}{\chi^{2}(m+1) /(N-m-1)}
$$

where the values $\chi^{2}(m)$ and $\chi^{2}(m+1)$ are the chi-squares of the linear regression line and second-order fitted curve with degrees of freedom of $N-m-1$, respectively. The variables $N$ and $m$ are the numbers of independent data points and terms of the fitting function, respectively. In this case, because we compare the linear regression line with the second-order fitted curve, the value $m$ is 2 . The number of independent data points usually becomes smaller than that of observed data points if there is a substantial autocorrelation at time lag $r \neq 0$ in time-series data. Therefore, we need to estimate the number of independent data points from the time-series data before we perform the above $F$-test. Here, we selected a way to estimate the number of independent data points as described by Chatfield (2013), and we calculated the number of independent data according to the following equation:

$$
N=\frac{n}{1+2 \sum_{r=1}^{n-1}\left(1-\frac{r}{n}\right) \rho(r)}
$$

where the variable $n$ is the number of observed data points and the function $\rho(r)$ is the autocorrelation function. If the value $F_{x}$ in Equation 1 is larger than the test value for $F$, we can be confident that the coefficient $c$ of the second-order fitted curve is not zero and that the secondorder fitted curve is suitable for the correlation between the monthly mean solar F10.7 index and Sq amplitude. Moreover, we checked the large/small relations of the coefficient of determinations $R$ for the linear regression and the second-order least-square fitted curves. This coefficient $R$ indicates how well the least-square curve fits the observation data, and it is given in the following equation:

$$
R=\sqrt{1-\frac{\sum_{i=1}^{n}(Y i-y i)^{2}}{\sum_{i=1}^{n}(Y i-\bar{Y})^{2}}}
$$

where the variables $Y, \bar{Y}$, and y are the Sq amplitude, the mean value of the Sq amplitude, and the one calculated with the linear regression line or the second-order least-square fitted curves, respectively. In this statistical analysis, we determined the second-order least-square fitted curves better than the linear regression line for the results that passed through the above $F$-test for the new additional terms and were satisfied with the large/small relation of the coefficient of determination of $R 2>R 1$ ( $R 1$ : linear regression line, $R 2$ : second-order least-square fitted curves). As a result of the statistical analysis, the Sq amplitude observed at 37 of 69 geomagnetic stations located in a region of less than $60^{\circ}$ in terms of the geomagnetic latitude passed through the present statistical test. From these results, it can be inferred that the relationship between the solar F10.7 index and Sq amplitude was approximately linear but there was weak nonlinearity for about $53 \%$ of the investigated stations.

In order to check whether the linear or nonlinear relationship between the solar F10.7 index and Sq amplitude depends on the latitude and longitude or not, we plotted the location of the 69 investigated geomagnetic stations on the world map with the blue and red triangles in Figure 1. Here, the blue and red triangles represent the geomagnetic stations that had linear or nonlinear relationships, respectively. In this case, because both blue and red triangles were very scattered on this map, there was no clear locality observed in the distribution of the investigated stations, thus indicating a nonlinear relationship.

Figure 5 shows the correlation between the monthly mean solar F10.7 index and Sq amplitudes in the equatorial ((a), (b)), low-latitude ((c), (d)), and middle-latitude ((e), (f)) regions. The green and red lines in each panel indicate the linear regression line and the second-order least-square fitted curve, respectively. The relationships shown in this figure were judged to be nonlinear with the present $F$-test results. In Figure 5, the Sq amplitude in the equatorial, low-, and middle-latitude regions tended to increase with an increase in the solar F10.7 index. This result indicates that the Sq amplitude was enhanced significantly during high solar activity as was already shown in Figures 2 and 4 . The deviation from the least-square fitted curves can be linked to various sources other than solar activity, including seasonal variations. Also as shown in Figure 5, the coefficients of determination of the least-square fitted curves tended to be small in the middle latitudes as compared with that in the equatorial region. This implies that the Sq amplitude in middle latitudes is influenced by other parameters such as the solar wind velocity and interplanetary magnetic field (IMF) in addition to the solar F10.7 index, which is considered a good indicator of the EUV radiation related to the formation of the ionosphere.

More importantly, Table 2 shows that the coefficient $c$ in the highest term of the fitted curve gives a negative value for the $\mathrm{Sq}$ amplitude in all the geomagnetic stations shown in Figure 5. This indicates that the shape of the fitted curve is concave down with the maximum at $\mathrm{x}=-\mathrm{d} / 2 \mathrm{c}$, and that the $\mathrm{Sq}$ amplitude tends to saturate for a high solar F10.7 index. A similar tendency can be seen in the Sq amplitude observed at 37 geomagnetic stations. Judging from the relationship between the solar F10.7 index and Sq amplitude on 

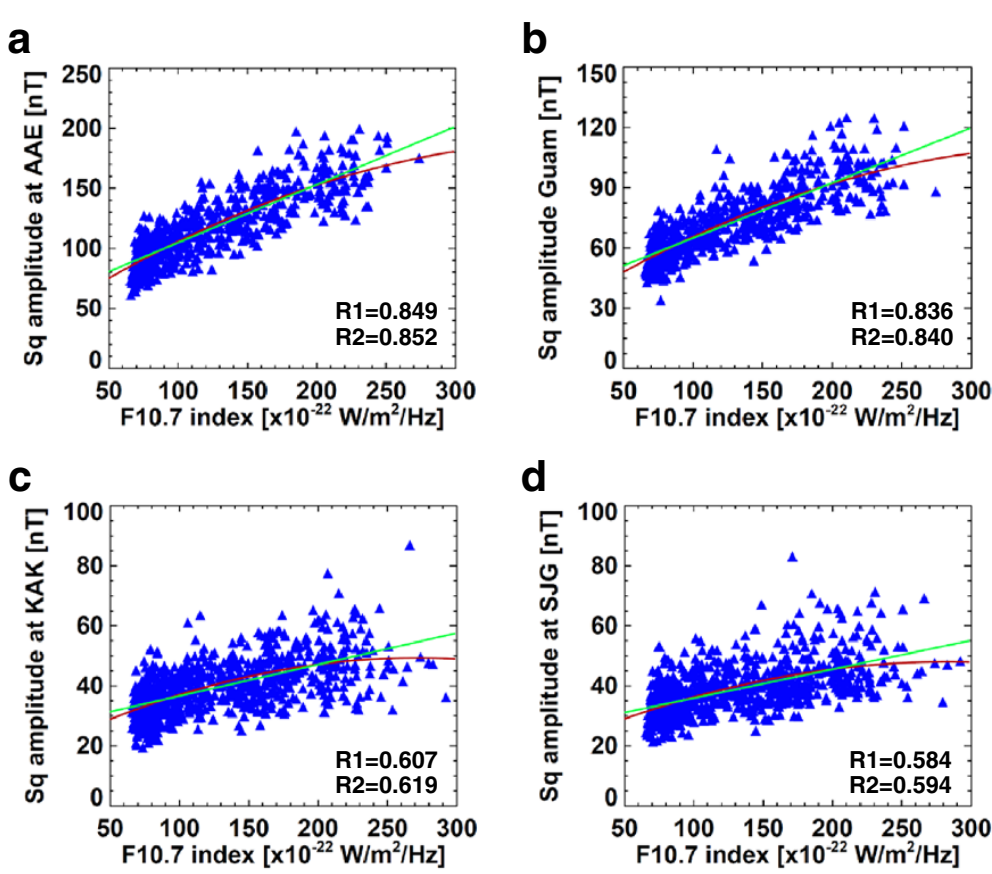

d
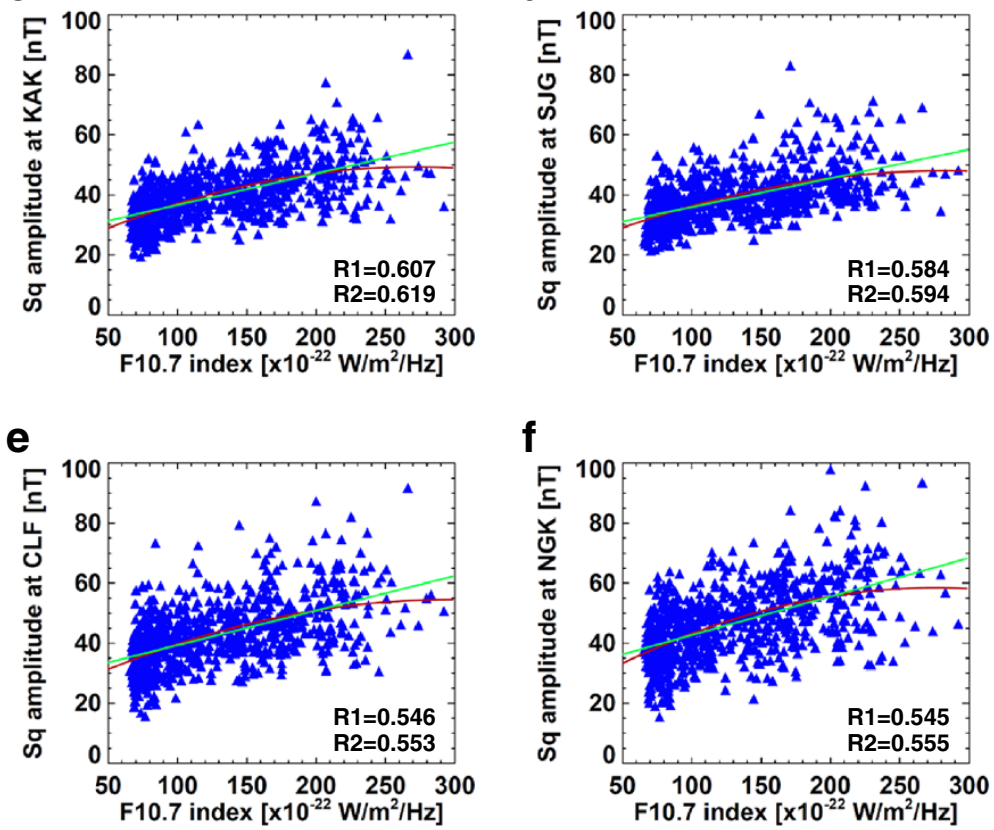

Figure 5 Correlation between the solar F10.7 index and Sq amplitudes. Correlation between the solar F10.7 index and Sq amplitudes obtained at Addis Ababa (AAE) (a), Guam (GUM) (b), Kakioka (KAK) (c), San Juan (SJG) (d), Chambon-La-Foret (CLF) (e), and Niemegk (NGK) (f). The green and red lines in each panel indicate the linear regression line and the second-order least-square fitted curve, respectively. The coefficients of determination R1 and R2 of the linear regression line and the second-order least-square fitted curve are shown in the right bottom of each panel. The Sq amplitude tends to be enhanced for the large values of the solar F10.7 index.

the basis of the F-test results, it is thought that the $\mathrm{Sq}$ amplitude tends to increase with an increase of the solar F10.7 with a weak nonlinearity indicating that the increasing rate tends to decrease for values of the solar F10.7 index.
Long-term variation in the residual Sq amplitude

In order to remove the effect of solar activity on the Sq amplitude obtained at each geomagnetic station, we calculated the residuals of the $\mathrm{Sq}$ amplitude as being the deviation from the least-square fitted curve, which

Table 2 List of three coefficients for the second-order fitted curve and coefficients of determination of the second-order fitted curve obtained at six geomagnetic stations

\begin{tabular}{lllll}
\hline Station name & Coefficient c & Coefficient d & Coefficient e & Coefficient of determination \\
\hline Addis Ababa & $-9.205 \times 10^{-4} \pm 2.654 \times 10^{-4}$ & $7.458 \times 10^{-1} \pm 7.693 \times 10^{-2}$ & $40.219 \pm 4.96$ & 0.848 \\
Guam & $-5.699 \times 10^{-4} \pm 1.541 \times 10^{-4}$ & $4.360 \times 10^{-1} \pm 4.428 \times 10^{-1}$ & $27.612 \pm 2.83$ & 0.840 \\
Kakioka & $-3.430 \times 10^{-4} \pm 9.720 \times 10^{-5}$ & $2.045 \times 10^{-1} \pm 2.869 \times 10^{-2}$ & $19.763 \pm 1.893$ & 0.598 \\
San Juan & $-3.056 \times 10^{-4} \pm 9.509 \times 10^{-5}$ & $1.850 \times 10^{-1} \pm 2.807 \times 10^{-2}$ & $20.711 \pm 1.848$ & 0.580 \\
Chambon-La-Foret & $-2.782 \times 10^{-4} \pm 1.361 \times 10^{-4}$ & $2.018 \times 10^{-1} \pm 4.015 \times 10^{-2}$ & $22.161 \pm 2.634$ & 0.540 \\
Niemegk & $-4.647 \times 10^{-4} \pm 1.413 \times 10^{-4}$ & $2.638 \times 10^{-1} \pm 4.168 \times 10^{-2}$ & $21.329 \pm 2.738$ & 0.544 \\
\hline
\end{tabular}


was already shown in Figure 5. As already described in Section "Correlation between the Sq amplitude and solar F10.7 index", the relationship between the solar F10.7 index and Sq amplitude is approximately linear but includes weak nonlinearity for some geomagnetic stations. In the present analysis, the residual Sq amplitude (Res-Sq) is defined by the following equation:

$$
\text { Res }-\mathrm{Sq}=Y-y
$$

where the meaning of the notation for $\mathrm{Y}$ and $\mathrm{y}$ is the same as the variables of Equation 3. In the F-test, when this relationship is judged to be linear, the value y of Equation 4 corresponds to the one calculated with the linear regression line. For the nonlinear case, the value $y$ is derived from the quadratic curve.

Figure 6 shows the long-term variation in the residual Sq amplitude obtained at Addis Ababa, Trivandrum, Kakioka, San Juan, Chambon-La-Foret, and Niemegk, which covers a wide latitudinal region from the dip equator to middle latitudes. The vertical scale is $\pm 40 \mathrm{nT}$ for all the geomagnetic stations. In this figure, the residual Sq amplitude at Addis Ababa, Trivandrum, and Chambon-La-Foret showed a weakly negative trend during the 70-year period, while that at Kakioka and San Juan did not show a clear trend. In order to check whether there was a significant trend in the residual Sq amplitude or not, we performed a trend

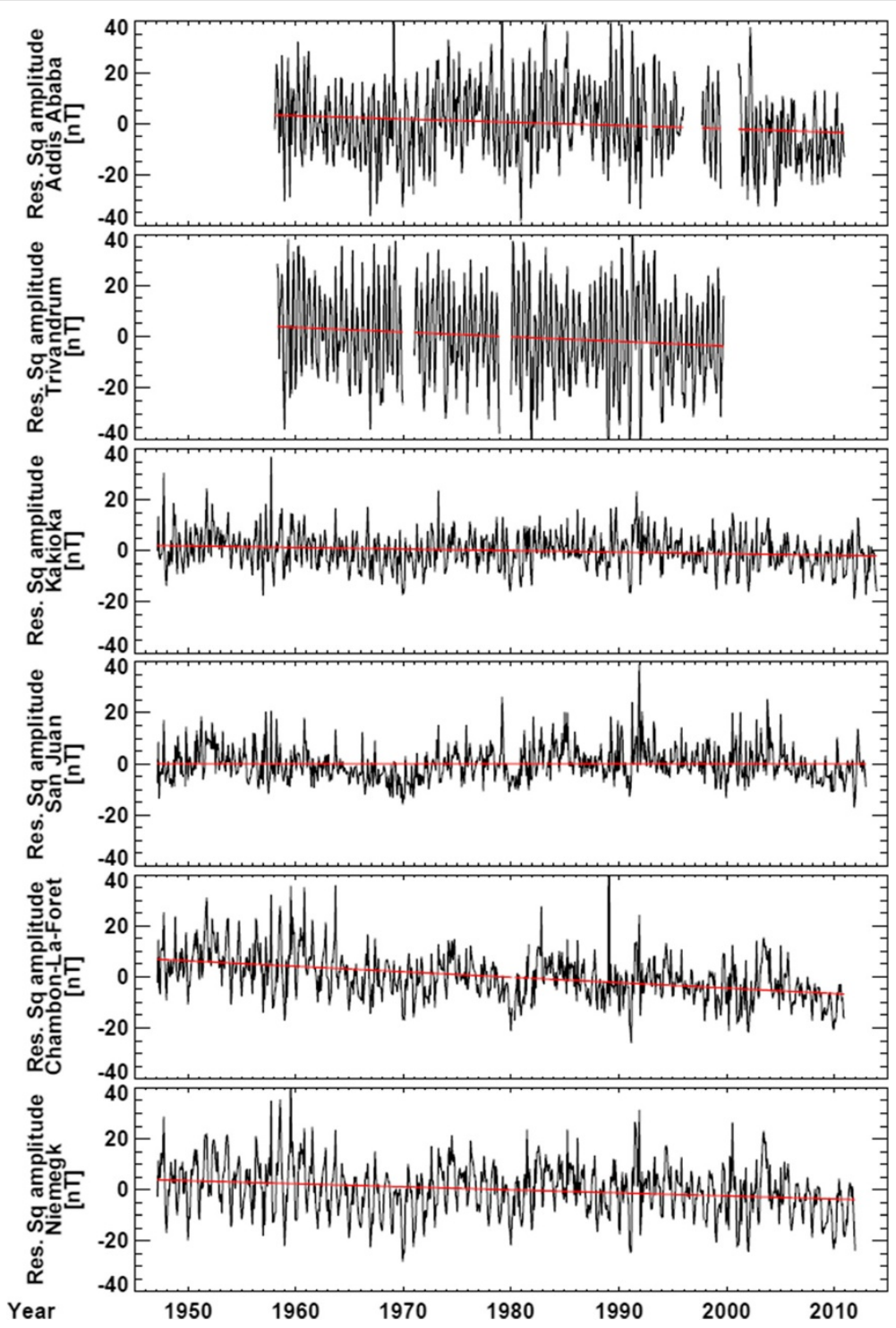

Figure 6 Long-term variation in the residual Sq amplitude obtained at six geomagnetic stations. (Addis Ababa, Trivandrum, Kakioka, San Juan, Chambon-La-Foret, and Niemegk). These stations cover a wide latitudinal region from the dip equator to middle latitudes. The vertical scale is $\pm 40 \mathrm{nT}$ for all the stations. 
test and regression analysis using a statistical analysis package included in the IUGONET data analysis tool. The trend test checks the tendency of the time-series data on the basis of the rank of the values of observation data. The trend test used in the present analysis is known as the Jonckheere-Terpstra test [Terpstra 1952; Jonckheere 1954]. The advantage of using this trend test is that we can easily test whether there is a monotonic trend in the time-series data without depending on the distribution of the data points. Because details of the trend test have been described in the book by Lehmann (1975), we only briefly give an overview here of the method for the trend test used in the present statistical analysis. In this trend test, we made a null hypothesis $\mathrm{H}_{0}$ that there is no increasing or decreasing trend in the residual $\mathrm{Sq}$ amplitude, and then we performed the trend test according to the following method. We first ranked the time-series data $x_{1}, x_{2}, x_{3}, \ldots x_{n}$ by the larger of the values, and then we represented the rank as the following variables:

$$
T_{1}, T_{2}, T_{3}, \ldots, T_{n}
$$

If the data sets have values with the same rank, we used a medium rank (for example, if the second and third data points were the same rank, the rank was 2.5). Here, we defined the statistical value $\mathrm{D}$ with the following equation:

$$
\begin{aligned}
D= & \left(T_{1}-1\right)^{2}+\left(T_{2}-2\right)^{2}+\cdots \\
& +\left(T_{n}-n\right)^{2}=\frac{1}{3} n(n+1)(2 n+1) \\
& -2 \sum_{i=1}^{n} i T_{i}
\end{aligned}
$$

The statistical value $\mathrm{D}$ gives the maximum value for the observation data with a monotonically increasing trend, but it becomes zero for the data with a monotonically decreasing trend. If the number of data points $n$ is large enough (at least $n \geq 10$ ), the two variables $E$ and $V$ can be specified by the following equations:

$$
\begin{aligned}
E & =\frac{n^{3}-n}{6} \\
V & =\frac{n^{2}(n+1)^{2}(n-1)}{36}
\end{aligned}
$$

and the statistical value $\mathrm{Z}$ becomes

$$
Z=\frac{D-E}{\sqrt{V}}
$$

Then, if the value $Z$ is satisfied with the relation $|Z|<z_{0}$, the null hypothesis $\mathrm{H}_{0}$ is adopted; that is, there is no significant trend in the time-series data. If $|Z| \geq z_{0}, \mathrm{H}_{0}$ is rejected. In that case, when the value $Z$ is positive, the time-series data have a significant increasing trend, and when the value $\mathrm{Z}$ is negative, there is a significant decreasing trend. Here, the value $Z_{0}$ is a critical value of the standard normal distribution corresponding to the equal tails of $\alpha(=0.05)$. After the trend test, we calculated the slope and standard error of the linear regression $(y=f x+g)$ for the residual $S q$ amplitude that passed through the trend test. Here, the variables $x$ and $y$ represent time and the residual Sq amplitude, respectively.

The results of the trend test and the slope and standard error derived from the linear regression analysis for six geomagnetic stations are shown in Table 3. The results of the trend test for the residual Sq amplitude with a significance level of $5 \%$ showed a significant decreasing trend at Addis Ababa, Trivandrum, Kakioka, Chambon-La-Foret, and Niemegk, while there was no trend at San Juan. The slope of the linear regression at Addis Ababa, Trivandrum, Kakioka, Chambon-La-Foret, and Niemegk was larger than the standard error of the slope. These results indicate that the long-term trend in the residual Sq amplitude depends on the location of the geomagnetic station.

In order to clarify the global distribution of the long-term trend in the residual Sq amplitude, we performed a trend test and linear regression analysis for the residual Sq amplitude obtained at 69 geomagnetic stations. In this statistical analysis, we also checked the results of the trend test with a significance level of $5 \%$. The results of the trend test for the residual Sq amplitude showed that 40 of 69 cases had a positive or negative trend during 1947 to 2013. Figure 7 shows the global distribution of the 40 residual Sq trends that passed through the trend test as a function of geographical latitude and longitude. The value of coefficient $\mathrm{f}$ derived from the linear regression analysis is indicated by a color scale of \pm 0.30 [nT/year]. In Figure 8, 29 cases of the 40 residual $\mathrm{Sq}$ trends showed a negative value with an

\begin{tabular}{|c|c|c|c|}
\hline $\begin{array}{l}\text { Station } \\
\text { name }\end{array}$ & $\begin{array}{l}\text { Trend } \\
\text { test }\end{array}$ & $\begin{array}{l}\text { Slope of linear } \\
\text { regression [nT/year] }\end{array}$ & $\begin{array}{l}\text { Standard error of } \\
\text { the slope [nT/year] }\end{array}$ \\
\hline Addis Ababa & Decrease & -0.125 & 0.084 \\
\hline Trivandrum & Decrease & -0.197 & 0.145 \\
\hline Kakioka & Decrease & -0.061 & 0.025 \\
\hline San Juan & No trend & 0.001 & 0.012 \\
\hline $\begin{array}{l}\text { Chambon-La- } \\
\text { Foret }\end{array}$ & Decrease & -0.216 & 0.035 \\
\hline Niemegk & Decrease & -0.120 & 0.037 \\
\hline
\end{tabular}
average of -0.15 [nT/year], and the observed locations of the negative trends were widely distributed all over the world. Especially in the European region, where many geomagnetic stations are concentrated, the majority of the residual $\mathrm{Sq}$ trends were negative. Also from the trend analysis results for the 69 investigated stations shown 


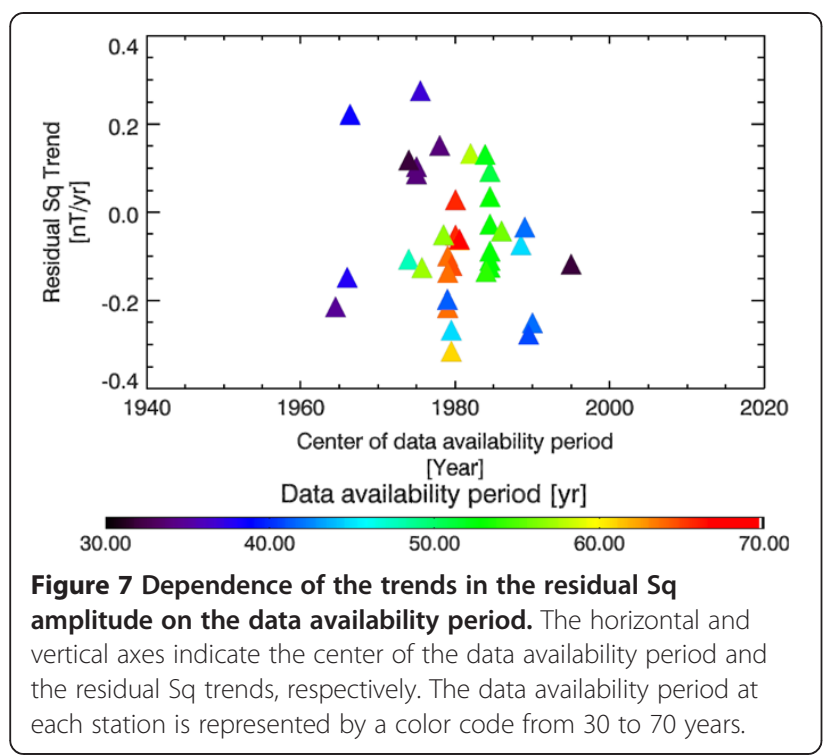

in Table 1, the residual Sq amplitude observed at Apia and Fredericksburg showed no trend while that observed at Hermanus showed an increasing trend during the investigated period. Therefore, in the present analysis, we could not find a significantly increasing trend in the residual Sq amplitude at Apia and Fredericksburg as was reported by Elias et al. (2010), who showed significant increases in the residual Sq amplitude at the above three stations during 1960 to 2001. Moreover, negative trends of the residual Sq amplitude with large absolute values of more than 0.10 [nT/year] were found in Europe, India, the eastern part of Canada, and New Zealand. The value of the negative trend at several European stations was less than -0.20 [nT/year]. However, positive trends of the residual Sq amplitude with large values of more than 0.20 [nT/year] were found at

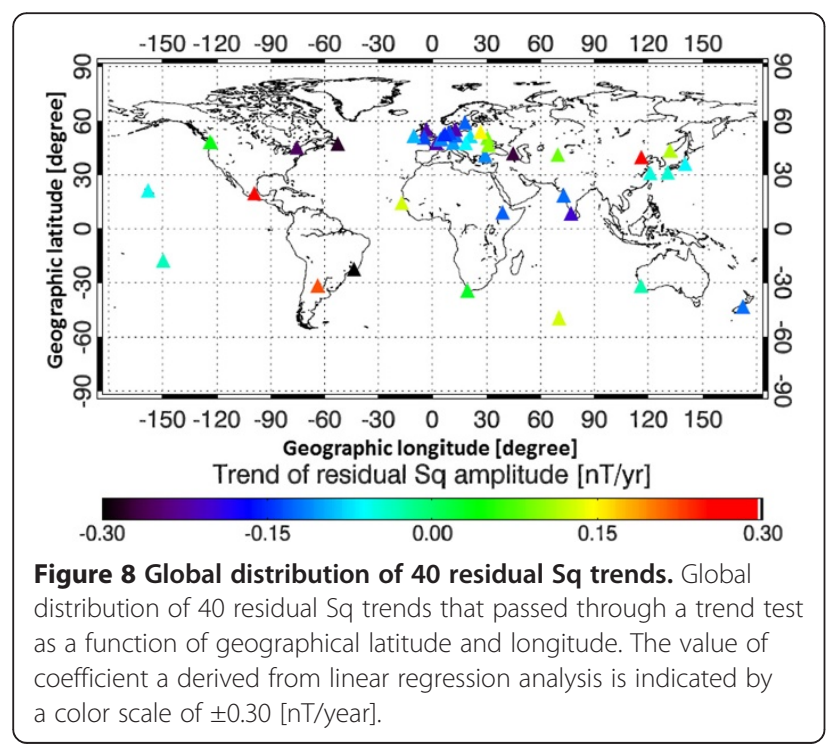

some stations on the Eurasia, North American, and South American continents.

In order to investigate the dependence of the trends in the residual $\mathrm{Sq}$ amplitude at 40 investigated stations on the data availability period, we analyzed the distribution of the trends in the residual Sq amplitude as functions of the data availability period and the center of the period. These results are shown in Figure 7. The horizontal and vertical axes in this figure indicate the center of the data availability period and the residual Sq trends, respectively. The data availability period at each station is represented by a color code ranging from 30 to 70 years. In Figure 7, the trends in the residual Sq amplitude were largely scattered without dependence on the parameters of the data availability period at each station. These results indicate that the difference of the data availability period at the different stations did not influence the long-term trends in the residual Sq amplitude.

\section{Elements to determine the Sq amplitude}

The Sq geomagnetic daily variation is mainly produced by ionospheric currents flowing in the $\mathrm{E}$ region of the ionosphere, where the ionospheric currents are driven by electric fields generated by the ionospheric dynamo. According to Ohm's law, the ionospheric current J obeys the following equation:

$$
\mathbf{J}=\sigma \cdot(\mathbf{E}+\mathbf{U} \times \mathbf{B})
$$

Here, $\sigma, \mathbf{E}, \mathbf{U}$, and $\mathbf{B}$ are the ionospheric conductivity, electric field, neutral wind velocity, and ambient magnetic field at each height, respectively. In order to obtain the net ionospheric current that produces the magnetic field perturbations on the ground, we have to integrate the right side of Equation 9 at every height. The electromotive force $(\mathbf{U} \times \mathbf{B})$ depends on both the atmospheric neutral wind and magnetic field intensity at the altitude of the $\mathrm{E}$ region of the ionosphere. Therefore, investigations of the longterm variation in the $\mathrm{Sq}$ amplitude enabled us to understand changes of ionospheric conductivities and atmospheric neutral winds associated with the long-term changes in the upper atmosphere. In the below subsections, we discuss the physical meaning of long-term variation in the Sq amplitude obtained by the present analysis of a large amount of geomagnetic field data.

\section{Extremely low Sq amplitude during the minimum of solar cycle $23 / 24$}

Sellek (1980) reported that the annual mean Sq amplitude observed at three equatorial to low-latitude stations (Huancayo, Hermanus, and San Juan) varies with strong dependence on an 11-year solar activity cycle, and in that study, the sunspot numbers were used as a good indicator of solar activity. He also showed that the Sq 
amplitude is almost linearly proportional to the annual mean number of sunspots. Furthermore, Sellek (1980) found significant secular variation in the Sq amplitude due to the secular changes in the Earth's magnetic field. The present study shows that the long-period component of the monthly mean Sq amplitude varies with correspondence to a 10- to 12-year solar activity cycle as seen in the monthly mean solar F10.7 index shown in Figures 2 and 4. The Sq amplitude tends to increase significantly during high solar activity. This result is similar to that shown in previous works e.g., Sellek (1980); Schlapp et al. (1990). A major cause of the enhancement of the Sq amplitude during high solar activity is thought to be (1) increased height-integrated ionospheric conductivities associated with an increase in the electron density of the ionosphere and (2) increased neutral wind velocity due to enhanced activity of solar tidal waves at the ionospheric height.

First, we discuss the second effect in regard to the variation of the Sq amplitude. Recently, using long-term ionospheric conductivity and geomagnetic field data obtained at low-latitude stations, Takeda (2013) showed that solar activity effects cannot be clearly seen in the thermospheric neutral winds, which are derived from the Sq amplitude calculated from the Y component of the geomagnetic field. He pointed out that a major contribution of the solar activity effects on the Sq amplitude is not through the neutral wind velocity but instead through the height-integrated ionospheric conductivity. More interestingly, Liu et al. (2004) reported that the amplitudes of the diurnal and semi-diurnal tides near the F2 peak electron density height (approximately $300 \mathrm{~km}$ ) estimated from the ionosonde observations at Yamagawa $\left(31.2^{\circ}, 130.6^{\circ}\right.$ in geographical coordinates) and Tomsk $\left(56.5^{\circ}, 84.9^{\circ}\right)$ are nonlinearly reduced for an increased solar F10.7 index. They interpreted the depression of the tidal wave amplitude during the high solar activity as an increase in ion drag force due to ion density enhancement. Sridharan et al. (2010) examined the long-term variations in the mean wind and tidal wave amplitude in the mesosphere and lower thermosphere using the wind data obtained from the medium-frequency (MF) radar at Tirunelveli near the equatorial region. Their results showed that the amplitude of meridional diurnal tidal waves tends to decrease with increasing solar activity. These wind observation results suggest that the ionospheric dynamo field is weak rather than strong during the solar maximum phase. However, the solar activity dependence of the ionospheric electric field during geomagnetically quiet periods, which correspond to the polarization electric field produced by the ionospheric dynamo field, is not clear [e.g., Berkey et al. 1990; Fejer et al. 1991; Buonsanto et al. 1993]. Therefore, because the electromotive force $(\mathbf{E}+\mathbf{U} \times \mathbf{B})$ shown in Ohm's law could be small during high solar activity, it can be concluded that the main contribution for the enhancement of the $\mathrm{Sq}$ amplitude is increased ionospheric conductivity during this period.

As shown in Figures 2 and 4, the Sq amplitude in the equatorial, low-latitude, and middle-latitude regions was the smallest near the solar cycle 23/24 minimum during 1947 to 2013. From the above discussion, the significant depression of the Sq amplitude implies that the EUV radiation responsible for the formation of the $\mathrm{E}$ region of the ionosphere was weaker during the solar cycle 23/24 minimum compared with that during the last solar cycle minimum. Solomon et al. (2010) investigated the long-term variation of the EUV radiation in a wavelength range of 26 to $34 \mathrm{~nm}$ within a period from 1996 to 2010 with data measured by the Solar EUV Monitor (SEM) [Judge et al. 1998] onboard the Solar and Heliospheric Observatory (SOHO) satellite. Their results showed that the EUV flux in a wavelength range of 26 to $34 \mathrm{~nm}$ was reduced by $15 \%$ from the minimum of solar cycle $22 / 23$ in 1996 to the minimum of solar cycle $23 / 24$ in 2008 to 2009. Moreover, Solomon et al. (2010) estimated the reduction in the solar EUV radiation at wavelengths from 1 to $105 \mathrm{~nm}$ using the solar EUV flux model for aeronomic calculations (EUVAC) [Richards et al. 1994] at a 1-nm resolution. The intensity of the solar EUV radiation in this wavelength showed a significant reduction by $5 \%$ to $30 \%$. As shown in Figure 2, the Sq amplitude at Guam in the equatorial region showed a significant reduction by approximately 10 nT (approximately 17\%) during the minimum of solar cycle $23 / 24$ in 2008 to 2009 compared with that during the minimum of solar cycle $22 / 23$ in 1996 . The same tendency can be seen in the Sq amplitude observed at the low- and middle-latitude stations. Therefore, the extreme reduction in the $\mathrm{Sq}$ amplitude during the minimum of solar cycle $23 / 24$ in 2008 to 2009 can be interpreted as a significant decrease in the ionospheric conductivity due to the significant reduction in solar EUV radiation, which is responsible for the formation of the ionosphere.

\section{Nonlinear response of the Sq amplitude to the solar F10.7 index}

It is well known that the magnitude of the Sq variation has good correlation with solar activity indices such as sunspot numbers and the solar F10.7 index [e.g., Sellek 1980; Schlapp et al. 1990; Macmillan and Droujinina 2007; Torta et al. 2009; Elias et al. 2010; Takeda 2013]. Sellek (1980) showed that the annual mean Sq amplitude obtained at San Juan at a low latitude is linearly proportional to the annual mean sunspot numbers using observation data during 1929 to 1965. Schlapp et al. (1990) also reported on the linear relationship between the sunspot numbers and Sq amplitude, but they pointed out that the position 
of the linear regression line is different for each solar cycle. Moreover, their analysis results [Schlapp et al. 1990] shown in the figure (Figure 3 ) suggest that the maximum value of the $\mathrm{Sq}$ amplitude tends not to become very large for an increase in sunspot numbers from 100 to 150 . The present statistical analysis results suggest that the relationship between the solar F10.7 index and Sq amplitude is approximately linear, but the response of the Sq amplitude obtained at 37 of 69 geomagnetic stations is nonlinear to the solar F10.7 index as shown in Figures 1 and 5. The rate of increase in the Sq amplitude decreases as the solar F10.7 index becomes high. On the basis of the present analysis results, the assumption of a linear relationship between the Sq amplitude and solar activity index used in the correlation analyses of previous works may not always be correct. Therefore, when we perform the correlation analysis between the solar activity index and the Sq amplitude in order to remove the effects of solar activity, we should consider this nonlinearity for the long-term analysis of the Sq variation at each geomagnetic station.

Related to the above discussion on the nonlinear relationship between the solar F10.7 index and Sq amplitude, many researchers have shown that the ionospheric electron density and total electron content (TEC) have a nonlinear response to the high solar F10.7 index and EUV flux [e.g., Balan et al. 1993, 1996; Liu et al. 2003, 2006]. Balan et al. (1993) investigated the relationship between the ionospheric TEC values and solar F10.7 index under magnetically quiet $(\mathrm{Ap}<10)$ equinoctial conditions during 1981 to 1985 . Their analysis results showed that the TEC values linearly increase with an increase in the solar F10.7 index but saturate around a large F10.7 value of more than 200. The TEC values almost become constant for F10.7 values in the range of 200 to 300. Balan et al. (1994) proposed that the ionospheric saturation effect is a possible consequence of the nonlinearity between the solar EUV flux and solar F10.7 index. Balan et al. (1994, 1996) mentioned that the ionospheric saturation effect cannot be seen in TEC or NmF2 against solar EUV flux data. In contrast, Liu et al. (2003) found that the saturation effect on the critical frequency of the F2 region of the ionosphere (foF2) appears for the EUV flux and pointed out that the daily ionospheric equatorial fountain and pre-reversal enhancement are important for saturation features in the equatorial to low-latitude regions. Recently, Liu et al. (2003) found the same feature for the response of peak electron density of the F2 region of the ionosphere (NmF2) to the EUV flux using the long-term ionosonde observation data obtained at 20 stations in the east Asia/Australia sector in addition to the nonlinearity between the F10.7 and EUV fluxes. On the basis of their analysis results, Liu et al. (2003) pointed out that not only the nonlinearity between the F10.7 and EUV fluxes but also dynamical effects in the atmosphere and ionosphere should be taken into account for solar activity dependence of the NmF2. Therefore, the nonlinearity between the F10.7 and EUV fluxes can be considered as one of the possible causes of the nonlinear response of the Sq amplitude to the solar F10.7 index. However, because the previous research of the response of ionospheric parameters to the solar F10.7 index and EUV flux was based on the analysis of the electron density variation in the $\mathrm{F}$ region above the $\mathrm{E}$ region of the ionosphere, it is worth investigating the response of the electron density in the $\mathrm{E}$ region corresponding to the dynamo region using long-term ionosonde observation data at several stations (for example, Kokubunji and Shigaraki) in future work.

\section{Effect of the high-latitude current system on the Sq variation in middle latitudes}

The geomagnetic field variation observed in middleto high-latitude regions is influenced by not only the ionospheric dynamo current system but also by other current systems originating from the large-scale fieldaligned currents (FACs) connecting the magnetosphere and polar ionosphere. Changes in the high-latitude current system might affect the Sq current system in the low and middle latitudes and depend on solar wind and IMF conditions. Kikuchi et al. (1996) investigated the latitudinal profile of the amplitude of the disturbance polar (DP) field 2 produced by the ionospheric electric field related to the high-latitude current system. The latitudinal profile of the DP 2 signature identified by the geomagnetic field variations showed a monotonic decrease with a decrease in geomagnetic latitude. The amplitude decreased by approximately $80 \%$ in the middle-latitude region $\left(30^{\circ}\right.$ to $\left.60^{\circ}\right)$ and by approximately $96 \%$ in the low-latitude region $\left(10^{\circ}\right.$ to $\left.30^{\circ}\right)$. This implies that the correlation between the magnetic field variation in the middle latitudes and solar F10.7 index becomes lower than that in the low latitudes. As shown in Table 2, the present analysis results show that the coefficient of determination of the fitted curve between the solar F10.7 index and Sq amplitude tends to decrease with an increase in geomagnetic latitude. This result suggests that the Sq amplitude in the middle latitudes is influenced by the high-latitude current system that expands to this region, even under geomagnetically quiet conditions. Recently, Vichare et al. (2012) investigated the Sq variation at Maitri $\left(66.84^{\circ} \mathrm{S}, 56.29^{\circ} \mathrm{E}\right.$ in geomagnetic coordinates) in the subauroral latitude region of the southern hemisphere during the minimum of solar cycle 23/24 in 2009 to 2010 in order to clarify the characteristics of seasonal variation of the Sq current system. Their analysis results showed that the Sq amplitude in the sub-auroral latitude regions during the summer is larger than during the winter, and that in spite 
of the total darkness during the winter, the Sq amplitude in the $\mathrm{D}$ component is 7 to $8 \mathrm{nT}$. Although the D-component variation could be thought of as magnetic field disturbances produced by large-scale FACs, Vichare et al. (2012) did not discuss an effect of the high-latitude current system on the Sq amplitude observed in the sub-auroral latitude region. This possibility should be examined by using the long-term observation data of geomagnetic fields in future studies.

Using long-term satellite observation data of solar wind and IMF near Earth, Lockwood et al. (2009) examined the solar activity dependence of the solar wind velocity and the strength of the IMF in a period from 1963 to 2008. Their results showed that the strength of the IMF tends to increase significantly during each solar cycle maximum while the solar wind velocity tends to increase during the declining phase of each solar cycle. However, Lockwood et al. (2009) did not analyze the long-term variation in the $\mathrm{Bz}$ component of the IMF, which is one of the important parameters for understanding the activity of the high-latitude current system. Weimer et al. (2010) created a statistical map of geomagnetic field variations in a region from high to middle latitudes as a function of the IMF using the geomagnetic field data obtained at 132 geomagnetic stations. The maximum and minimum values shown in the statistical maps depended on the southward IMF magnitude, solar wind velocity, and seasons. However, Weimer et al. (2010) did not show the solar cycle dependence on the magnitude and pattern of geomagnetic field variation because they used the geomagnetic field data for only 4 years. In order to clarify the contribution of solar wind energy to the long-term variation in the Sq amplitude at mid-latitudes, it would be valuable to compare the residual Sq amplitude with the interplanetary parameters (solar wind density, velocity, and IMF) in future studies.

\section{Global distribution of long-term variation in the residual Sq amplitude}

In previous works, it has been shown that there is a significant positive trend in the residual Sq amplitude at several geomagnetic stations e.g., Sellek (1980); Schlapp et al. (1990); Elias et al. (2010). Elias et al. (2010) reported that significant positive trends can be seen in the long-term variation of the residual Sq amplitude obtained at three geomagnetic stations at low latitude. However, because Elias et al. (2010) analyzed the geomagnetic field data obtained at only three stations during 1960 to 2001, the global distribution of long-term trends in the residual Sq amplitude has remained unknown. Moreover, their analysis period was too short to clarify characteristics of the long-term variation in the residual Sq amplitude. In the present study, we found the global distribution of long-term trends during 1947 to 2013 using the long-term observation data of the geomagnetic field obtained at many stations, which are globally distributed in a region raging from the middle latitudes to the equator.

As a result, a majority of the long-term variation in the residual $\mathrm{Sq}$ amplitude showed a significant negative trend. A systematic dependence on the geographical latitude or longitude could not be seen in the spatial distribution of the occurrence of the negative $\mathrm{Sq}$ trend. The trend was much stronger in Europe, India, the eastern part of Canada, and New Zealand. The value of the negative trend at four geomagnetic stations in several European stations was less than -0.20 [nT/year]. Conversely, a positive trend of the residual Sq amplitude with large values of more than 0.20 [nT/year] can be seen at only three geomagnetic stations on the Eurasia, North American, and South American continents. This result suggests that an enhancement of the Sq amplitude due to a cooling effect in the upper atmosphere associated with global warming, as proposed by Elias et al. (2010), cannot be detected at all of the geomagnetic stations, which are globally distributed in a region from the middle latitudes to the equator. If an enhancement of ionospheric electron density in the $\mathrm{E}$ region of the ionosphere where the dynamo current flows anticlockwise in the northern hemisphere is considered to be caused by a cooling effect in the upper atmosphere as shown in simulation studies [Roble and Dickinson 1989; Rishbeth 1990], then the negative trend in the residual Sq amplitude implies that there exist other possible mechanisms to suppress a contribution of the cooling effect in the upper atmosphere to the residual $\mathrm{Sq}$ amplitude. Recently, Cnossen and Richmond (2013) investigated the contribution of changes in the secular variation of the Earth's magnetic field to long-term trends in the ionosphere, thermosphere, and $\mathrm{Sq}$ variation for three specific years (1908, 1958, and 2008) using the CMIT model. They showed that the major changes in the $\mathrm{Sq}$ amplitude take place between approximately $40^{\circ} \mathrm{S}$ to $40^{\circ} \mathrm{N}$ and approximately $100^{\circ} \mathrm{W}$ to $50^{\circ} \mathrm{E}$, which correspond to the South Atlantic region where the secular variation of the Earth's magnetic field is the largest. The simulated changes in the Sq amplitude were \pm 5 to $\pm 10 \mathrm{nT} /$ century $\left( \pm 5 \times 10^{-2}\right.$ to $\pm 10 \times 10^{-2}$ $\mathrm{nT} /$ year). Using the same upper atmospheric model as Cnossen and Richmond (2013), De Haro Barbas et al. (2013) estimated the global distribution of the difference between the Sq amplitude in 2008 and 1958 derived from the $\mathrm{H}$ component of the geomagnetic field. In Figure 2 [De Haro Barbas et al. 2013], the largest difference of the Sq amplitude can be seen near the dip equator around the South Atlantic anomaly region where the magnetic field intensity is depressed significantly compared with that in other regions. The northern and southern regions at the center of the dip equator showed positive and negative variations of the Sq amplitude. The value reached $\pm 20 \mathrm{nT}$ 
$( \pm 0.4 \mathrm{nT} /$ year$)$. Cnossen and Richmond (2013) interpreted the significant changes in the $\mathrm{Sq}$ amplitude as the displacement of the equatorial electrojet due to secular variation of the magnetic field inclination. In the present study, such long-term variation of the Sq amplitude could not be detected near the South Atlantic anomaly region because of the small number of geomagnetic stations distributed in this region. De Haro Barbas et al. (2013) also showed that small negative variation of the Sq amplitude can be seen in Europe, India, the eastern part of America, and the southern part of China. The value of the negative Sq trend was ranged from -0.1 to $0.0 \mathrm{nT} /$ year. The regions of the negative $\mathrm{Sq}$ trend cover the geomagnetic stations where the negative trends in the residual Sq amplitude were detected in this study. Because the values of the $\mathrm{Sq}$ trends derived from the observation data were smaller than those from the model calculations, this result suggests that the Sq trends cannot be explained by only the secular variation of the ambient magnetic field.

In order to confirm whether the changes in both the magnetic field intensity and inclination are strongly related to the long-term variation in the residual Sq amplitude or not, we investigated the relationship using the long-term magnetic field data calculated with the IGRF-11 model [Finlay et al. 2010]. In this analysis, we performed a 1-year running average of the residual Sq amplitude in order to remove the seasonal variation with a period of 1 year or less. The period of the magnetic field calculation corresponds to the available period of geomagnetic field data obtained from each station. Figure 9 shows the relationship between the residual
Sq amplitude and the ambient magnetic field parameters (total intensity and inclination) at the Addis Ababa (left panels $a$ and b) and Chambon-La-Foret (right panels $\mathrm{a}$ and b) stations. The Addis Ababa and Chambon-La-Foret stations are located near the dip equator and in the middle-latitude region, respectively. The calculation altitude of the ambient magnetic field was at $100-\mathrm{km}$ altitude near the dynamo layer of the ionosphere. As shown in the left panels a and b, the residual $\mathrm{Sq}$ amplitude near the dip equator showed no significant correlation with the magnetic field intensity but the Sq amplitude tended to decrease with an increase of the magnetic field inclination. The correlation coefficients in both cases were 0.030 and -0.656 , respectively. From these results, it can be mentioned that the residual Sq amplitude observed near the dip equator depends strongly on the magnetic field inclination. The long-term variation in the residual Sq amplitude near the dip equator can be interpreted as the movement of the equatorial electrojet due to secular variation of the magnetic field inclination [e.g., Cnossen and Richmond 2013; De Haro Barbas et al. 2013]. Moreover, as shown in the right panels $\mathrm{a}$ and $\mathrm{b}$, the residual $\mathrm{Sq}$ amplitude observed at the Chambon-La-Foret station in the middle-latitude region showed a significant decrease with an increase of the magnetic field intensity while the residual Sq amplitude showed an increase with an increase of the magnetic field inclination. The correlation coefficients in both cases were -0.727 and 0.680 , respectively. However, since the ionospheric conductivity at the E-region height in the middle latitude does not vary much with changes in
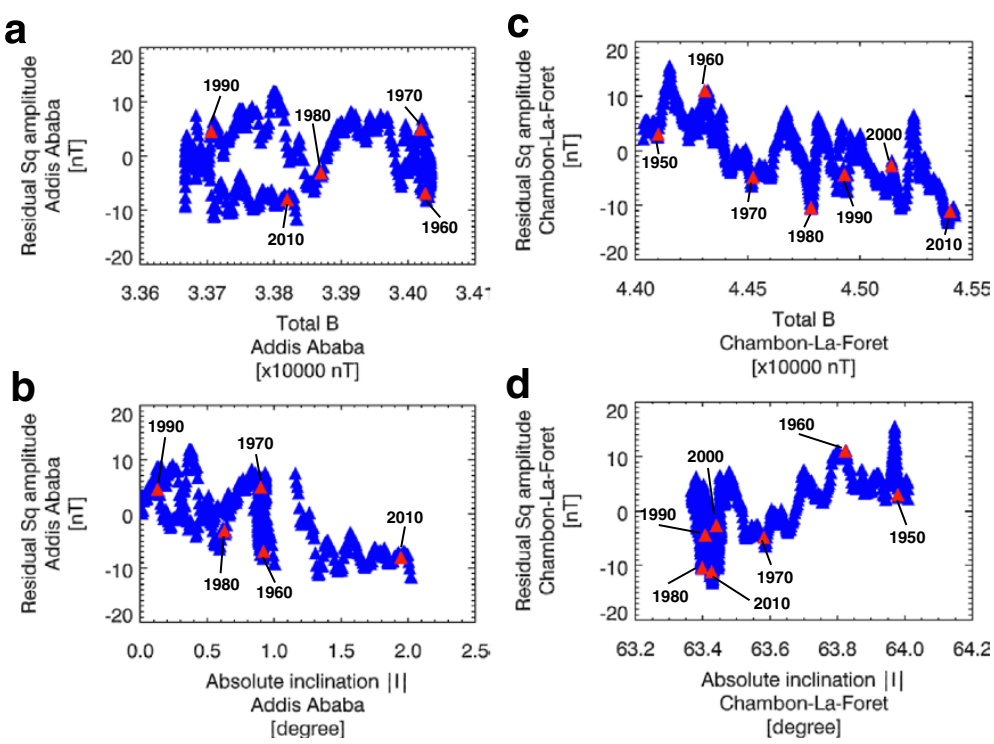

Figure 9 Relationship between the residual Sq amplitude and the ambient magnetic field parameters. Relationship between the residual Sq amplitude and the ambient magnetic field parameters (total intensity and inclination) at the Addis Ababa (left panels $\mathbf{a}$ and $\mathbf{b}$ ) and Chambon-La-Foret (right panels $\mathbf{c}$ and $\mathbf{d}$ ) stations. The Addis Ababa and Chambon-La-Foret stations are located near the dip equator and in the middle-latitude region, respectively. The red marks in each panel indicate the values on January 1950, 1960, 1970, 1980, 1990, 2000, and 2010. 
the magnetic field inclination and the variation of the magnetic field inclination is relatively small in the right panel (b) in Figure 9, it is difficult to interpret this correlation as dependence of the residual $\mathrm{Sq}$ amplitude on the magnetic field inclination. Therefore, from the results shown in the right panel (a) in Figure 9, it can be considered that the long-term variation in the residual Sq amplitude is mainly due to the decrease of the ionospheric conductivities associated with the secular variation of the magnetic field intensity [e.g., Takeda 1996; Elias et al. 2010].

Next, we investigated the global distribution of correlation coefficients between the magnetic field intensity, inclination, and residual $\mathrm{Sq}$ amplitude obtained from 40 geomagnetic stations. Figure 10 shows the global distribution of correlation coefficients between the magnetic field intensity and residual Sq amplitude (panel a) and between the magnetic field inclination and residual Sq amplitude (panel b). The value of the correlation coefficients is indicated by a color scale of \pm 1.0 . Only the correlation coefficients that passed through a $t$-test with a significance level of $95 \%$ are plotted on the world map. In panel a of Figure 10, 25 of 35 cases

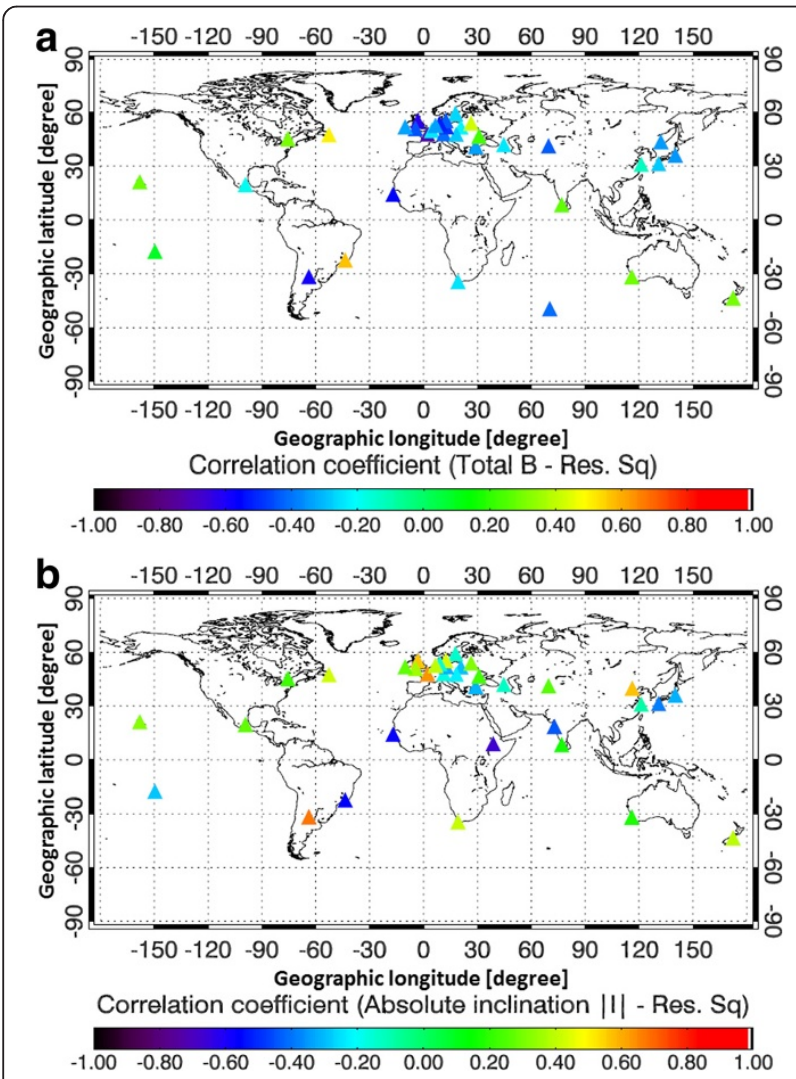

Figure $10 \mathrm{Global}$ distribution of correlation coefficients. Global distribution of correlation coefficients between the magnetic field intensity and residual Sq amplitude (a) and between the magnetic field inclination and residual $\mathrm{Sq}$ amplitude (b) as a function of geographical latitude and longitude. The value of the correlation coefficient is indicated by a color scale of \pm 1.0 . showed an anti-correlation between the magnetic field intensity and residual Sq amplitude. Moreover, most of the residual $\mathrm{Sq}$ amplitudes in Europe and Japan where the geomagnetic stations are densely distributed indicated this relationship. Meanwhile, the rest of the residual Sq amplitude showed a positive correlation with the ambient magnetic field intensity. This result suggests that the residual Sq amplitude is not anti-correlated with the intensity of the ambient magnetic field at all the geomagnetic stations all over the world. Takeda (1996) and Elias et al. (2010) showed with model calculations that ionospheric conductivity tends to increase because of a decrease of the ambient magnetic field intensity. Assuming that the effect of the polarization electric field and electromotive force on the secular variation of the ambient magnetic field intensity is much smaller than that of the ionospheric conductivity, the anti-correlation between the residual $\mathrm{Sq}$ amplitude and ambient magnetic field intensity could be thought of as begin caused by the anti-correlation of ionospheric conductivity and ambient magnetic field intensity. However, on the basis of only the present data analysis results, we could not clarify the reason for the positive correlation between the residual $\mathrm{Sq}$ amplitude and ambient magnetic field. In panel b of Figure 10, the global distribution of the correlation coefficients between the absolute value of the magnetic field inclination and residual $\mathrm{Sq}$ amplitude showed that the signs of the coefficients were different for different geomagnetic stations without a dependence on the geographic latitude and longitude. Therefore, in the present analysis, we could not identify a global feature of the effect of the absolute value of the magnetic field inclination on the long-term variation in the residual Sq amplitude. In future studies, we need to compare the Sq amplitude with the ionospheric conductivities derived from the IRI (International Reference Ionosphere) [Bilitza et al. 2012, NRL-MISIS (Naval Research Laboratory Mass Spectrometer and Incoherent Scatter Radar Exosphere) [Picone et al. 2002], and IGRF-11 models over a long period of time.

\section{Conclusions}

Characteristics of long-term variation in the amplitude of solar quiet (Sq) geomagnetic field daily variation have been investigated using 1-h geomagnetic field data obtained from 69 geomagnetic observation stations within the period of 1947 to 2013. The Sq amplitude observed at these geomagnetic stations showed a clear dependence on the 10- to 12-year solar activity, and it tended to increase during each solar maximum phase. Especially, a significant depression in the $\mathrm{Sq}$ amplitude occurred around the minimum of solar cycle 23/24 in 2008 to 2009, and the amplitude was the smallest in the data analysis period (1947 to 2013). However, this depression cannot be 
seen in the solar F10.7 index compared with that during the minimum of solar cycle $22 / 23$ in 1995 to 1996 . The correlation analysis between the $\mathrm{Sq}$ amplitude and solar F10.7 index showed that the $\mathrm{Sq}$ amplitude tends to increase with an increase in the solar F10.7 index but saturates for a high F10.7 value of 150 or more. On the basis of this correlation analysis result, it can be said that the relationship between the solar F10.7 index and $\mathrm{Sq}$ amplitude is approximately linear but includes a weak nonlinearity for about $53 \%$ of the investigated stations. Because the production rate of electrons and ions should be proportional to the solar EUV flux, this nonlinear effect could be linked to the nonlinear relationship between the solar F10.7 and EUV flux, or the chemical loss processes of ionospheric ions, or the dynamical effects of ionospheric plasma, or a combination of these factors. In order to remove the effect of solar activity seen in the long-term variation in the Sq amplitude, we calculated a linear or second-order fitting curve between the solar F10.7 index and Sq amplitude during 1947 to 2013 and examined the residual $\mathrm{Sq}$ amplitude, which was defined as the deviation from the fitted curve. As a result, a majority of the trends in the residual Sq amplitude that passed through a trend test showed negative values over a wide region. This tendency was relatively strong in Europe, India, the eastern part of Canada, and New Zealand. The relationship between the magnetic field intensity and residual Sq amplitude showed an anticorrelation for about $71 \%$ of the geomagnetic stations. Meanwhile, the residual Sq amplitude in the equatorial station (Addis Ababa) was anti-correlated with the absolute value of the magnetic field inclination. This implies that there was movement of the equatorial electrojet due to secular variation of the ambient magnetic field.

\section{Competing interests}

The authors declare that they have no competing interests.

\section{Authors' contributions \\ AS has analyzed long-term observation data of geomagnetic field obtained at 274 geomagnetic stations using the IUGONET data analysis system, developed the data analysis tool to calculate the Sq amplitude, and drafted the manuscript. YK and MN established the observation database of the geomagnetic field and revised the manuscript. TH, YO, and AY have contributed to discussions on the scientific contents and revised the manuscript. All authors read and approved the final manuscript.}

\footnotetext{
Acknowledgements

This work was supported by the Inter-university Upper Atmosphere Global Observation NETwork (IUGONET) project, which is funded by the Ministry of Education, Culture, Sports, Science and Technology (MEXT), Japan, the joint research program of the Solar-Terrestrial Environment Laboratory, Nagoya University, and JSPS (Japan Society for the Promotion of Science) KAKENHI grant Nos. 22253006, 23740369, and 26200478. We used the geomagnetic Kp index and long-term geomagnetic field data provided by the World Data Center for Geomagnetism, Kyoto University and GeoForschungsZentrum (GFZ) Potsdam, respectively.
}

\section{Author details}

${ }^{1}$ Research Institute for Sustainable Humanosphere (RISH), Kyoto University, Uji, Japan. ${ }^{2}$ World Data Center for Geomagnetism, Kyoto University, Kyoto, Japan. ${ }^{3}$ Solar-Terrestrial Environment Laboratory, Nagoya University, Nagoya, Japan.

Received: 28 March 2014 Accepted: 11 November 2014

Published online: 11 December 2014

\section{References}

Abe S, Umemura N, Koyama Y, Tanaka Y, Yagi M, Yatagai A, Shinbori A, UeNo S, Sato Y, Kaneda N (2014) Progress of the IUGONET system - metadata database for the upper atmosphere ground-based observation data. Earth Planets Space 66:133. doi:10.1186/1880-5981-66-133

Balan N, Bailey GJ, Jayachandran B (1993) Ionospheric evidence for a nonlinear relationship between the solar e.u.v. and $107 \mathrm{~cm}$ fluxes during an intense solar cycle. Planet Space Sci 41:141-145

Balan N, Bailey GJ, Jenkins B, Rao PB, Moffett RJ (1994) Variations of ionospheric ionization and related solar fluxes during an intense solar cycle. J Geophys Res 99:2243-2253

Balan N, Bailey GJ, Su YZ (1996) Variations of the ionosphere and related solar fluxes during solar cycles 21 and 22. Adv Space Res 18:11-14

Berkey JE, Richmond AD, Barnes RM, Gonzalez S, Tepley CA (1990) Solar cycle variations in $\mathrm{F}$ region electrodynamic drifts at Arecibo. J Geophys Res 95:4303-4306. doi:10.1029/JA095iA04p04303

Bevington PR, Robinson DK (2003) Data Reduction and Error Analysis for the Physical Sciences, 3rd edition. McGraw-Hill Higher Education, New York, USA

Bhardwaj SK, Subba Rao PBV (2013) Secular trend of geomagnetic elements in the Indian region. Earth Planets Space 65:1515-1523

Bilitza D, Brown SA, Wang MY, Souza JR, Roddy PA (2012) Measurements and IRI model predictions during the recent solar minimum. J Atmos Solar Terr Phys 86:99-106. doi:10.1016/j.jastp.2012.06.010

Bloxham J, Gubbins D (1985) The secular variation of the Earth's magnetic field. Nature 317:777-781

Bremer J (1998) Trends in the ionospheric E and F regions over Europe. Ann Geophys 16:986-996

Buonsanto MJ, Hagan ME, Salah JE, Fejer BG (1993) Solar cycle and seasonal variations in F region electrodynamics at Millstone Hill. J Geophys Res 98:15,677-15,683. doi:10.1029/93JA01187

Campbell WH (1982) Annual and semiannual changes of the quiet daily variations (Sq) in the geomagnetic field at North American locations. J Geophys Res 87:785-796. doi:10.1029/JA087iA02p00785

Campbell WH (1997) Introduction to Geomagnetic Fields. Cambridge University Press, Cambridge, pp 67-109

Chapman S, Bartels J (1940) Geomagnetism, vol I. Oxford University Press, Oxford

Chatfield C (2013) The Analysis of Time Series: An Introduction, 6th edition. CRC Press LLC, Boca Raton, FL, USA

Chulliat A, Vigneron P, Thebault E, Sirol O, Hulot G (2013) Swarm SCARF dedicated ionospheric field inversion chain. Earth Planets Space 65:1,271-1,283

Cloutier PA, Haymes RC (1968) Vector measurement of the mid-latitude Sq ionospheric current system. J Geophys Res 73:1,771-1,787. doi:10.1029/ JA073i005p01771

Cnossen I (2014) The importance of geomagnetic field changes versus rising CO2 levels for long-term change in the upper atmosphere. J Space Weather Space Clim 4: doi:10.1051/swsc/2014016

Cnossen I, Richmond AD (2008) Modeling the effects of changes in the Earth's magnetic field from 1957 to 1997 on the ionospheric hmF2 and foF2 parameters. J Atmos Solar Terr Phys 70:1512-1524

Cnossen I, Richmond AD (2013) Changes in the Earth's magnetic field over the past century: effects on the ionosphere-thermosphere system and solar quiet (Sq) magnetic variation. J Geophys Res 118:849-858. doi:10.1029/ 2012JA018447

Cnossen I, Richmond AD, Wiltberger M (2012) The dependence of the coupled magnetosphere-ionosphere-thermosphere system on the Earth's magnetic dipole moment. J Geophys Res 117:A05302. doi:10.1029/2012JA017555

Danilov AD (2002) Overview of trends in the ionospheric E and F2 regions. Phys Chem Earth 27:579-588

Danilov AD, Konstantinova AV (2012) Variations in foF2 at the end of the 1990s and the beginning of the 2000s according to the SPIDR system data. Geomagn Aeron 52:350-355 
Danilov AD, Mikhailov AV (1999) Long-term trends in the parameters of the F2-region: a new approach. Geomagn Aeron 39:473-479

De Haro Barbas BF, Elias AG, Cnossen I, de Artigas MZ (2013) Long-term changes in solar quiet (Sq) geomagnetic variations related to Earth's magnetic field secular variation. J Geophys Res 118:3712-3718. doi:10.1002/jgra.50352

Elias AG (2009) Trends in the F2 ionospheric layer due to long-term variations in the Earth's magnetic field. J Atmos Solar Terr Phys 71:1602-1609

Elias AG, Ortiz de Adler N (2006) Earth magnetic field and geomagnetic activity effects on long-term trends in the F2 layer at mid-high latitudes. J Atmos Solar Terr Phys 68:1871-1878

Elias AG, Artigas MZ, Barbas BFH (2010) Trends in the solar quiet geomagnetic field variation linked to the Earth's magnetic field secular variation and increasing concentrations of greenhouse gases. J Geophys Res 115:A08316. doi:10.1029/2009JA015136

Elias AG, De Haro Barbas BF, Shibasaki K, Souza JR (2014) Effect of solar cycle 23 in foF2 trend estimation. Earth Planets Space 66:111. doi:10.1186/1880-5981-66-111

Fejer BG, dePaula ER, González SA, Woodman RF (1991) Average vertical and zonal F region plasma drifts over Jicamarca. J Geophys Res 96:13,901-13,906. doi:10.1029/91JA01171

Finlay CC, Maus S, Beggan CD, Bondar TN, Chambodut A, Chernova TA, Chulliat A, Golovkov VP, Hamilton B, Hamoudi M, Holme R, Hulot G, Kuang W, Langlais B, Lesur V, Lowes FJ, Luhr H, Macmillan S, Mandea M, McLean S, Manoj C, Menvielle M, Michaelis I, Olsen N, Rauberg J, Rother M, Sabaka TJ, Tangborn A, Tøffner-Clausen L, Thebault E, et al. (2010) International geomagnetic reference field: the eleventh generation. Geophys J Int 183:1216-1230. doi:10.1111/j.1365-246X.2010.04804.X

Foppiano AJ, Cid L, Jara V (1999) lonospheric long-term trends for South American mid-latitudes. J Atmos Solar Terr Phys 61:717-723

Hall CM, Cannon PS (2002) Trends in foF2 above Tromsø. Geophys Res Lett 29:2128. doi:10.1029/2002GL016259

Hawary RE, Yumoto K, Yamazaki Y, Mahrous A, Ghamry E, Meloni A, Badi K, Kianji G, Uiso CBS, Mwiinga N, Joao L, Affluo T, Sutcliffe PR, Mengistu G, Baki P, Abe S, Ikeda A, Fujimoto A, Tokunaga T (2012) Annual and semi-annual Sq variations at $96^{\circ} \mathrm{MM}$ MAGDAS I and II stations in Africa. Earth Planets Space 64:425-432

Hayashi HY, Koyama T, Hori Y, Tanaka S, Abe A, Shinbori M, Kagitani T, Kouno D, Yoshida S, UeNo N, Kaneda M, Yoneda N, Umemura H, Tadokoro T, Motoba, IUGONET project team (2013) Inter-university upper atmosphere global observation network (IUGONET). Data Sci J 12:WDS179

Hirono M (1952) A theory of diurnal magnetic variation in equatorial regions and conductivity of the ionosphere e region. J Geomagn Geoelectr 4:5-21

Hongre L, Hulot G, Khokhlov G (1998) An analysis of the geomagnetic field over the past 2000 years. Phys Earth Planet Inter 106:311-335

Jonckheere AR (1954) A distribution-free k-sample test against ordered alternatives. Biometrika 41:133-145

Judge DL, McMullin DR, Ogawa HS, Hovestadt D, Klecker B, Hilchenbach M, Mobius E, Canfield LR, Vest RE, Watts R, Tarrio C, Kuehne M, Wurz P (1998) First solar EUV irradiances obtained from SOHO by the CELIAS/SEM. Sol Phys 177:161. doi:10.1023/A:1004929011427

Kikuchi T, Lühr H, Kitamura T, Saka O, Schlegel K (1996) Direct penetration of the polar electric field to the equator during a DP2 event as detected by the auroral and equatorial magnetometer chains and the EISCAT radar. J Geophys Res 101:17,161-17,173. doi:10.1029/96JA01299

Korte M, Constable C (2011) Improving geomagnetic field reconstructions for 0-3 ka. Phys Earth Planet Inter 188:247-259

Lastovicka J, Solomon SC, Qian L (2012) Trends in the neutral and ionized upper atmosphere. Space Sci Rev 168:113-145. doi:10.1007/s11-214-011-9799-3

Lehmann EL (1975) Nonparametrics: Statistical Methods Based on Ranks. Holden-Day, San Francisco

Liu JY, Chen Yl, Lin JS (2003) Statistical investigation of the saturation effect in the ionospheric foF2 versus sunspot, solar radio noise, and solar EUV radiation. J Geophys Res 108:1067. doi:10.1029/2001JA007543

Liu L, Luan X, Wan W, Lei J, Ning B (2004) Solar activity variations of equivalent winds derived from global ionosonde data. J Geophys Res 109:A12305. doi:10.1029/2004JA010574

Liu L, Wan W, Ning B, Pirog OM, Kurkin VI (2006) Solar activity variations of the ionospheric peak electron density. J Geophys Res 111:A08304. doi:10.1029/2006JA011598

Lockwood M, Rouillard AP, Finch ID (2009) The rise and fall of open solar flux during the current grand solar maximum. Astrophys J Acoust Soc Am 700:937-944. doi:10.1088/0004-637X/700/2/937
Macmillan S, Droujinina A (2007) Long-term trends in geomagnetic daily variation. Earth Planets Space 59:391-395

Matsushita S (1960) Seasonal and day-to-day changes of the central position of the Sq overhead current system. J Geophys Res 65:3835-3839. doi:10.1029/ JZ065i011p03835

Matsushita S, Campbell WH (1967) Solar quiet and lunar daily variation fields. In: Physics of Geomagnetic Phenomena, vol 1. Acad Press, pp 301-424

Mikhailov AV (2006) Trends in the ionospheric E-region. Phys Chem Earth 31:22-33

Mikhailov AV, Marin D (2000) Geomagnetic control of the foF2 long-term trends. Ann Geophys 18:653-665

Nahayo E, Kotze PB (2012) Polynomial modelling of CHAMP satellite data to investigate rapid secular variation fluctuations over southern Africa during 2003 and 2004. Earth Planets Space 64:595-603

Picone JM, Hedin AE, Drob DP, Aikin AC (2002) NRLMSISE-00 empirical model of the atmosphere: statistical comparisons and scientific issues. J Geophys Res 107:1468. doi:10.1029/2002JA009430

Qian L, Lastovicka J, Solomon SC, Roble RG (2011) Progress in observations and simulations of global change in the upper atmosphere. J Geophys Res 116:A00H03. doi:10.1029/2010JA016317

Richards PG, Fennelly JA, Torr DG (1994) EUVAC: a solar EUV flux model for aeronomic calculations. J Geophys Res 99:8981. doi:10.1029/94JA00518

Richmond AD, Matsushita S, Tarpley JD (1976) On the production mechanism of electric currents and fields in the ionosphere. J Geophys Res 81:547-555

Rishbeth H (1985) The quadrupole ionosphere. Ann Geophys 3:293-298

Rishbeth H (1990) A greenhouse effect in the ionosphere? Planet Space Sci 38:945-948

Rishbeth H, Roble RG (1992) Cooling of the upper atmosphere by enhanced greenhouse gases. Modeling of the thermospheric and ionospheric effects. Planet Space Sci 40:1011-1026

Roble RG, Dickinson RE (1989) How will changes in carbon dioxide and methane modify the mean structure of the mesosphere and thermosphere? Geophys Res Lett 16:1441-1444

Schlapp DM, Butcher EC (1995) Seasonal and sunspot-cycle changes in the day-to-day variability of Sq. Geophys J Int 120:173-185

Schlapp DM, Sellek R, Butcher EC (1990) Studies of worldwide secular trends in the solar daily geomagnetic variation. Geophys J Int 100:469-475

Sellek R (1980) Secular trends in daily geomagnetic variations. J Atmos Solar Terr Phys 42:689-695

Solomon SC, Woods TN, Didkovsky LV, Emmert JT, Qian L (2010) Anomalously low solar extreme - ultraviolet irradiance and thermospheric density during solar minimum. Geophys Res Lett 37:L16103. doi:10.1029/2010GL044468

Sridharan S, Tsuda T, Gurubaran S (2010) Long-term tendencies in the mesosphere/lower thermosphere mean winds and tides as observed by medium-frequency radar at Tirunelveli $\left(8.7^{\circ} \mathrm{N}, 77.8^{\circ} \mathrm{E}\right)$. J Geophys Res 115: D08109. doi: 10.1029/2008JD011609

Takeda M (1996) Effects of the strength of the geomagnetic main field on the dynamo action in the ionosphere. J Geophys Res 101:7875-7880

Takeda M (2002) Features of global geomagnetic Sq field from 1980 to 1990. J Geophys Res 107. doi:10.1029/2001JA009210

Takeda M (2013) Contribution of wind, conductivity, and geomagnetic main field to the variation in the geomagnetic Sq field. J Geophys Res 118:4516-4522. doi:10.1002/jgra.50386

Tanaka Y, Shinbori A, Hori T, Koyama Y, Abe S, Umemura N, Sato Y, Yagi M, UeNo S, Yatagai A, Ogawa Y, Miyoshi Y (2013) Analysis software for the upper atmosphere data developed by the IUGONET project and its application to the polar science. Adv Polar Sci 24:231-240. doi:10.3724/SPJ.1085.2013.00231

Terpstra TJ (1952) The asymptotic normality and consistency of Kendall's test against trend, when ties are present in one ranking. Indag Math 14:327-333

Torta JM, Gaya Pique LR, Curto JJ, Altadill D (2009) An inspection of the long-term behavior of the range of the daily geomagnetic field variation from comprehensive modelling. J Atmos Solar Terr Phys 71:1497-1510

Torta JM, Marsal S, Curto JJ, Gaya-Pique LR (2010) Behaviour of the quiet-day geomagnetic variation at Livingston Island and variability of the Sq focus position in the South American-Antarctic Peninsula region. Earth Planets Space 62:297-307

Vichare G, Rawat R, Hanchinal A, Sinha AK, Dhar A, Pathan BM (2012) Seasonal evolution of Sq current system at sub-auroral latitude. Earth Planets Space 64:1023-1031

Weimer DR, Clauer CR, Engebretson MJ, Hansen TL, Gleisner H, Mann I, Yumoto K (2010) Statistical maps of geomagnetic perturbations as a function of the interplanetary magnetic field. J Geophys Res 115:A10320. doi:10.1029/ 2010JA015540 
Yamazaki Y, Yumoto K (2012) Long-term behavior of annual and semi-annual Sq variations. Earth Planets Space 64:417-423

Yatagai A, Tanaka Y, Abe S, Shinbori A, Yagi M, UeNo S, Koyama Y, Umemura N, Nosé M, Hori T, Sato Y, Hashiguchi NO, Kaneda N, IUGONET project team

(2014) Interuniversity upper atmosphere global observation network (IUGONET) meta-database and analysis software. Data Sci J 13:PDA37-PDA43

Yue X, Liu L, Wan W, Wei Y, Ren Z (2008) Modeling the effects of secular variation of geomagnetic filed orientation on the ionospheric long term trend over the past century. J Geophys Res 113:A10301. doi:10.1029/ 2007JA012995

doi:10.1186/s40623-014-0155-1

Cite this article as: Shinbori et al: Long-term variation in the upper atmosphere as seen in the geomagnetic solar quiet daily variation. Earth, Planets and Space 2014 66:155.

Submit your manuscript to a SpringerOpen ${ }^{\circ}$ journal and benefit from:

- Convenient online submission

- Rigorous peer review

- Immediate publication on acceptance

- Open access: articles freely available online

- High visibility within the field

- Retaining the copyright to your article

Submit your next manuscript at $\gg$ springeropen.com 